Florida International University

FIU Digital Commons

FIU Electronic Theses and Dissertations

University Graduate School

$10-24-2011$

\title{
The Relationship Between a Retention Program and the Persistence and Graduation Rates of First- Generation Low-Income Students at an Urban, Public University
}

Dorret E. Sawyers

Florida International University, sawyersd@fiu.edu

DOI: $10.25148 /$ etd.FI1 1120908

Follow this and additional works at: https://digitalcommons.fiu.edu/etd

\section{Recommended Citation}

Sawyers, Dorret E., "The Relationship Between a Retention Program and the Persistence and Graduation Rates of First-Generation Low-Income Students at an Urban, Public University" (2011). FIU Electronic Theses and Dissertations. 532.

https:// digitalcommons.fiu.edu/etd/532

This work is brought to you for free and open access by the University Graduate School at FIU Digital Commons. It has been accepted for inclusion in FIU Electronic Theses and Dissertations by an authorized administrator of FIU Digital Commons. For more information, please contact dcc@fiu.edu. 


\section{FLORIDA INTERNATIONAL UNIVERSITY \\ Miami, Florida}

THE RELATIONSHIP BETWEEN A RETENTION PROGRAM AND THE PERSISTENCE AND GRADUATION RATES OF FIRST-GENERATION LOWINCOME STUDENTS AT AN URBAN, PUBLIC UNIVERSITY

A dissertation submitted in partial fulfillment of the

requirements for the degree of

DOCTOR OF EDUCATION

in

HIGHER EDUCATION ADMINISTRATION

by

Dorret E. Sawyers 


\section{To: Dean Delia Garcia}

College of Education

This dissertation, written by Dorret E. Sawyers, and entitled The Relationship Between a Retention Program and the Persistence and Graduation Rates of First-Generation, Low Income Students at an Urban, Public University, having been approved in respect to style and intellectual content, is referred to you for judgment.

We have read this dissertation and recommend it to be approved.

$\begin{array}{r}\text { Delia Garcia } \\ \hline \text { Linda Spears-Bunton } \\ \hline \text { Benjamin Baez } \\ \hline \text { Glenda Droogsma-Musoba, Major Professor }\end{array}$

Date of Defense: October 24, 2011

The dissertation of Dorret E. Sawyers is approved

\begin{tabular}{r}
\hline $\begin{array}{r}\text { Dean Delia Garcia } \\
\text { College of Education }\end{array}$ \\
\hline Dean Lakshmi N. Reddi \\
University Graduate School
\end{tabular}

Florida International University, 2011 


\section{DEDICATION}

To my husband and children, for their constant love and support, and to my mother for all the sacrifices she made for my education and upbringing. 


\section{ACKNOWLEDGMENTS}

Sincere thanks to my major professor, Dr. Glenda Musoba for her help during the development and completion of this work, and to my committee members, Dr. Delia Garcia, Dr. Linda Spears-Bunton, and Dr. Benjamin Baez for their encouragement and support. 


\begin{abstract}
OF THE DISSERTATION
THE RELATIONSHIP BETWEEN A RETENTION PROGRAM AND THE PERSISTENCE AND GRADUATION RATES OF FIRST-GENERATION LOWINCOME STUDENTS AT AN URBAN, PUBLIC UNIVERSITY
\end{abstract} by

Dorret E. Sawyers

Florida International University, 2011

Miami, Florida

Professor Glenda Musoba, Major Professor

The purpose of this study was to examine the relationship between participation in a retention program designed to promote academic and social integration and the persistence rates of first generation, low-income college students at an urban, public multiethnic university. Archival data were collected from the university's Office of Institutional Research and the retention program office and included SAT/ACT scores, GPA, gender, ethnicity, and program participation data. A total of 292 first-generation, low-income students who were admitted to the university in the summer of 1999 were identified for the study. A group of 166 students were selected for the comparison group because they had not participated in the retention program; 126 students had participated in the retention program.

Three major research questions guided this study: (a) Are there differences in persistence rates and other academic characteristics of underprepared, low-income, first generation college students who participate and do not participate in the retention program?; (b) Does involvement in the retention program predict student persistence of 
first generation low-income, underprepared students?, and (c) Can predictors of GPA be identified for students in the retention program using program and descriptive variables?

A series of logistic regression analyses were conducted to assess the relationship between various retention services and the persistence and graduation rates of participants. The results showed that there were statistically significant relationships between participation and non-participation in the retention program and having higher GPAs and higher graduation and persistence rates. Of the four program features, participation in tutoring, workshops, and social events were found to be predictors of graduation. College GPA was also found to be a predictor of graduation for all students. The results also showed that women were more likely to graduate than men. 


\section{TABLE OF CONTENTS}

CHAPTER

PAGE

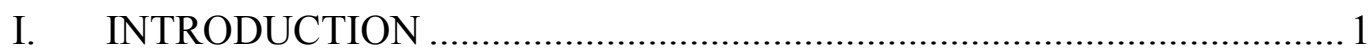

Purpose of the Study and Research Questions ...................................... 2

Significance of the Study ..................................................................... 2

Theoretical Model .................................................................................... 3

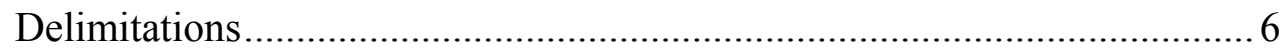

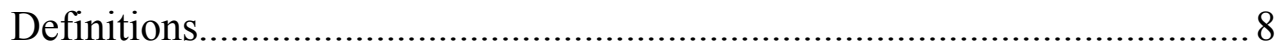

Overview of the Study ............................................................... 10

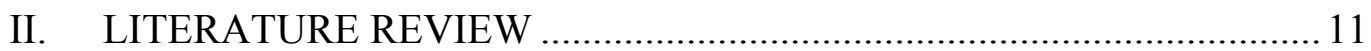

Background Characteristics .............................................................. 11

Other Studies on Non-Traditional First Generation Students.................... 13

First Generation Students' Characteristics and Challenges ....................... 15

Studies on Minority Students ............................................................. 22

First Generation Students' Needs ...................................................... 26

Research on Program Intervention in General ......................................... 30

Research on Program Intervention for At-Risk Students ........................ 32

Conclusion..................................................... 36

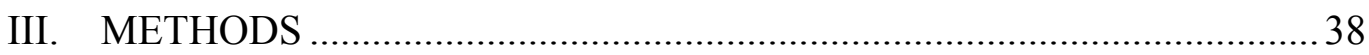

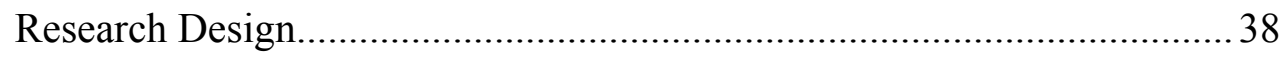

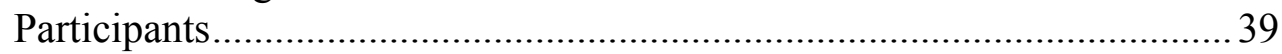

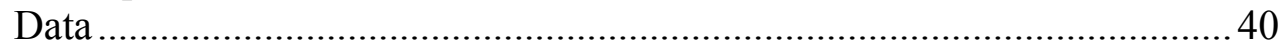

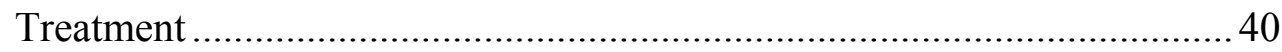

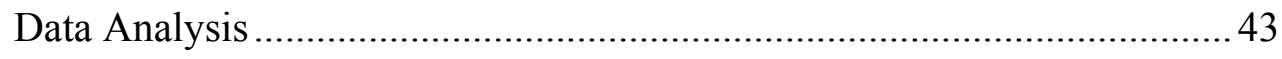

IV. RESULTS ............................................................................... 44

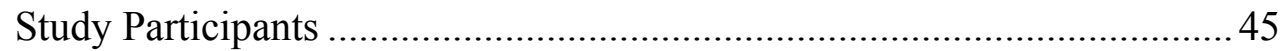

Retention Program Descriptive Data .................................................... 48

Findings for the Research Questions .................................................. 49

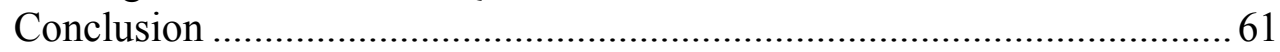

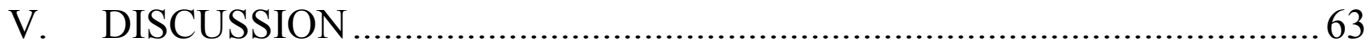

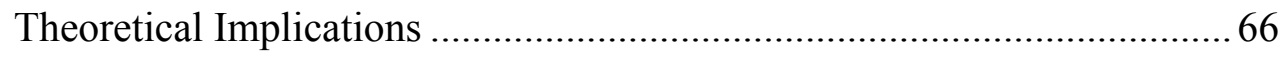

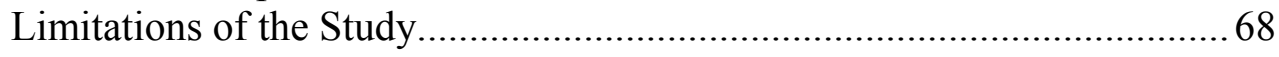

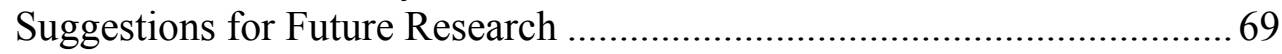

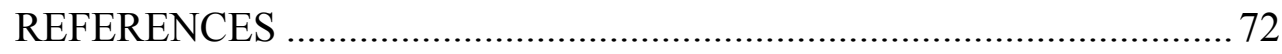

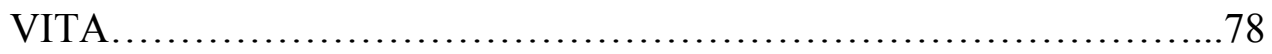




\section{CHAPTER I}

\section{INTRODUCTION}

Institutions of higher education have been charged with educating an increasing number of ethnically/racially/linguistically diverse students from a variety of cultural/geographic/class backgrounds. Between 1984 and 1998 the total number of White undergraduates in institutions of higher education increased by $5.1 \%$; however, although at the same time, the number of Asian American, Hispanic, African American, and Native American undergraduates increased by 61\% (Pascarella \& Terenzini, 1998). Although a larger percentage of minority and low-income students and an increasing number of students who are first in their family to attend college are entering institutions of higher education, many of these individuals fail to graduate. One group of students that educators are trying to understand better than in the past are those students who are the first in their family to attend college because the persistence and graduation rates for these students remain low (Levin \& Levin, 1991).

The relationship between social and academic integration and the persistence rates of first generation college students is not fully understood and merits further study. Although we know first generation students do not persist as well as students whose parents went to college (Pascarella, Pierson, Wolniak, \& Terenzini, 2004), we know little why this is so. Importantly, programs designed to enhance retention for first generation students have not been well studied (Braxton, McKinney, \& Reynolds, 2006; Patton, Morelon, Whitehead, \& Hossler, 2006). The results of this study demonstrate the relationship between persistence and academic and social integration through participation in a program for first generation students. For the present study, first 
generation is defined as students whose parent (s) did not complete a bachelors degree (Chaney, Muraskin, Cahalan \& Goodwin (1998). First generation status is important because students in the retention group had to be from first generation, low-income or disabled status. Also, the retention program was funded by the U.S. Department of Education to serve this population whose retention and graduation rates have remained low.

\section{Purpose of the Study and Research Questions}

The purpose of this study was to examine the relationship between participation in a retention program designed to promote academic and social integration and the persistence rates of under-prepared, low-income, first generation college students at an urban public multiethnic university. Three major research questions guided this study:

1. What are the differences in persistence rates and other academic characteristics of underprepared, low-income, first generation college students who participate and do not participate in the retention program?

2. To what extent does involvement in the retention program predict persistence of first generation college students?

3. Can predictors of GPA be identified for students in the retention program using program and descriptive variables?

\section{Significance of the Study}

Research studies examining the relationship that institutional retention efforts have on graduation and persistence have been minimal, and institutional program evaluations have lacked the necessary rigor to meet accepted standards for published 
research (Braxton, McKinney \& Reynolds(2006); Patton, Morelon, Whitehead \& Hossler(2006). Therefore, quasi-experimental comparison studies such as this one are necessary to help examine the usefulness of institutional retention programming. This study seeks to contribute to the existing research on persistence among first generation low-income students by empirically examining the relationship of an academic and social integration strategy on persistence rates of first-generation college students at an urban, public university.

\section{Theoretical Model}

For the present study retention program intervention is based on Van Gennep's (1960) rites of passage theory. Van Gennep noted the use of certain rituals as necessary to a person's integration into a new environment. Tinto's (1975) theory of a causal relationship between social and academic integration with students persistence built upon Van Gennep's theory. Tinto's (1975) model of student departure began in collaboration with Cullen in 1973. Part of Cullen's previous research investigated and reviewed longitudinal studies on student attrition; Tinto applied these data to theoretical model of attrition. Although the academic and social integration variables formed the foundation for Tinto's (1975) model, his subsequent inclusion of additional environmental variables were adapted from Van Gennep's (1960) rites of passage theory and Durkheim's(1951) theories of suicide and departure further developed by Spady (1970).

Durkheim (1951) explained that four specific types of suicide occur within society, one of which he labeled egotistical, which is defined as an individual's inability to become integrated into the community. This failure he stated could be rooted in either an intellectual or a social phenomenon. He also noted that egotistical suicide tended to 
occur when one failed to become integrated into the new environment. Tinto's (1975) extension of the ideas of integration and rites of passage into the higher education arena provided examples of a student's need to navigate through the higher education system and to acclimate in a specific learning environment. An individual's failure to acclimate to a certain learning environment continued to be the focus of Tinto's studies on student departure from the college setting. While Durkheim's (1951) theory is based on permanent withdrawal from society, Spady's (1970) theoretical model investigated the student dropout process, noting that because students have specific characteristics and specific goals, academic performance was a dominant influence on students' behavior. Tinto (1993) used egotistical departure as the model for explaining student departure from the system.

Tinto’s $(1975,1987)$ model of student departure hypothesizes that a match between individual academic ability and motivations with parallel institutional academic and social characteristics is positively associated with persistence or retention in the program or university. Students bring individual attributes such as pre-college schooling, aptitude and ability, as well as cultural family background characteristics to the university. In turn, these attributes affect the degree of acculturation into the institution's social and academic culture. Tinto reasoned that the students' level of integration into the culture of the institution's academic and social structures is related to the decision to drop out or persist in university studies.

Also, researchers (Bean \& Metzner, 1985;Pascarella \& Terenzini, 1998; Tierney, 1992) have cited weaknesses in Tinto’s (1975) early model of persistence. For example, Tinto asserted that students need to "break away" from past associations and traditions to 
become better integrated into the college's social and academic milieu. Tierney (1992) argued that this transitional model, from which Tinto drew this concept of breaking away, is not applicable to minority college students because the model was intended to describe developmental progression within a culture rather than assimilation from one culture to another. Furthermore, given that minority students' cultural backgrounds often differ from the Eurocentric frameworks upon which the norms and values at predominantly White institutions (PWI) are based, Tierney (1999) argued that this aspect of Tinto's theory ignores bicultural integration, or the ability of minority students to succeed at college while being part of both the majority and minority cultures.

Tinto (1998) later included stages of separation, transition, and incorporation indicating these factors played an integral role into why students leave college. Separation, the first stage of the students' college career, requires students to disassociate themselves from the membership in their past communities (e.g. local high school and place of residence). The transition stage is the period of passage between the old and the new. Having begun the process of separating themselves from the past, new students have yet to acquire the norms and patterns of behavior appropriate to integrate in the new communities of the college. The next stage of incorporation is marked by students finding and adopting norms appropriate to the new college setting and establishing competent membership in the social and intellectual communities of college life. Tinto also acknowledged the need to include ethnographic information as background variables in his 1975 model on persistence. Tinto also included psychological, societal, economic, organizational, and interaction factors in his 1987 revision of his previous work, supported by previous findings by Metzner \& Bean (1987). 
Tinto's (1987) theory has been tested with traditional students with some support for the theory but has not received complete confirmation (Nora \& Cabrera, 1996). Tinto's theory has not been as rigorously tested with academically under-prepared, lowincome, diverse, first-generation students. Nora and Cabrera found confirmation for some aspects but not all. Further, although Nora and Cabrera's sample were much more diverse than Tinto's original work, their students still did not carry all the risk factors of the students in the current study.

Following Tinto's (1975) theory, the retention program in this study included a holistic combination of academic and social integration strategies focused on helping participating students in the first year. The first year focus of the intervention was chosen because freshmen are usually at the highest risk of attrition, especially if first-year status is compounded with other challenges such as first-generation status, low family incomes, and being academically under-prepared. Following the theory of social integration, strong social networks among program participants and with staff are promoted on the basis of similar backgrounds because emphasis is placed on hiring staff who are from first-generation, low-income backgrounds. Academic intervention strategies include peer tutoring, supplemental instruction, academic advising, and an early alert warning system and are designed to foster academic integration consistent with Tinto's (1975) theory.

\section{Delimitations}

This study is delimited to a particular retention program at an urban, public university where the cultural diversity is unique. Although the general student population at this Hispanic-serving institution (HIS) is approximately $60 \%$ Hispanic, $12.5 \%$ African American, and 17\% White, the292 students (originally 320; however, after careful 
review of enrollment dates of program participants, it was discovered that 28 of the participants had a different enrollment date from summer 1999) who fit the criteria for this study were $40 \%$ African American, 45\% Hispanic, and the remaining 15\% were a combination of other ethnic/racial groups. This sample is a reflection of the firstgeneration, underprepared students who attend the institution. The university is unique, in that it is an HSI and a research university. This demographic is unusual and provide a rich sample for this study. Further it is an understudied population in the higher education literature. Thus understanding garnered from this study offers valuable information on students from a majority minority institution and on the strategies that are related to their persistence and retention. This study was housed at an urban, HSI in the southeast, with an enrollment of over 38,000 students (University Website, March 2008). Both Spanish and English are spoken by many students and staff; however, English is the language of instruction. The overall 4-year retention rate is approximately $57 \%$, typical of public universities with low selectivity. Also typical is the tendency of the freshman population to have the highest attrition, with over $20 \%$ of freshmen dropping out during or immediately following their first year. Persistence rates for low-income first-generation, academically-underprepared students are lower.

The researcher in this study is an administrator at the institution and was supervising this program. However, the study used historical quantitative data; therefore, the dual roles would not introduce bias into the study. While this study was contextualized to this particular campus, the sample size, comparison group of nonparticipants, and variability within the sample suggested broader implications for the 
results. In order to provide a collective understanding of the context and features of the study, a shared understanding of some of the terminology used in the study is important.

\section{Definitions}

In order to provide a collective understanding of the context and features of the study, a shared understanding of some of the terminology used in the study is important.

\section{Academic Integration}

Academic integration refer to the development of a strong affiliation with the college academic environment both in the classroom and outside of class, which includes interactions with faculty, academic and support services staff, and peers when of an academic nature (e.g., peer tutoring, study groups; Nora\& Cabrera, 1993; Tinto, 1987).

\section{Attrition}

Attrition is defined as when a student who enters college with the intention of graduating due to personal or institutional reasons leaves school for an extended period of time and does not re-enroll at the original or any other institution.

\section{Bridge Programs}

Precollege programs that assist students in accessing post-secondary education by providing services such as additional instruction or programs to help students acclimate to college life are called Bridge programs. Many are TRIO funded and include a summer pre-college component. They can last from a few weeks to a full academic year. The Federal TRIO Programs are educational opportunity outreach programs designed to motivate and support students from disadvantaged backgrounds. The term TRIO is not an acronym and refers to the number of U.S. Department of Education's federal programs (originally 3 now 7) designed to increase access to higher education for economically 
disadvantaged students to progress through the academic pipeline from middle school to post-baccalaureate programs.

\section{First-Generation}

Some define first-generation status as students whose parents never attended college, but this study follows a widely used definition of first-generation as neither parent had completed a bachelor's degree (Chaney \& Associates, 1998; U.S. Department of Education, 1996). Because the financial and status benefits of a college education accrue most to those who acquire the credential of the degree, degree completion is the better definition for this study. Further, the selection criteria of the treatment program used this definition based on the external, federal funding requirements.

\section{Persistence}

Persistence is defined as the student graduated or was still enrolled at the same institution 6 years after initial enrollment. Continuing enrollment at 6 years is also coded as persistence because students who are still enrolled are still on a positive path toward completion. Although there are multiple definitions of persistence including from the first to the second semesters of the first year, the stronger measures of actual educational attainment include a longer time span. Graduation within 1.5 times the expected is most common(6 years for a 4-year degree)

\section{Retention}

Retention refers to the extent to which students remain enrolled at the institution as they work toward achieving their academic goals. Retention is often used interchangeably with persistence and is the more preferred term to describe programs and services designed to help students stay in school in this study. 


\section{Social Integration}

Social integration refers to the development of a strong affiliation with the college social environment both in the classroom and outside of class, including interactions of a social nature with faculty, academic and support services staff, and peers (e.g., peer group interactions, informal contact with faculty and staff, and involvement in social organizations; Nora \& Cabrera 1993). These all play a vital role in the study, as students enter the program and progress towards graduation.

\section{Overview of the Study}

The study sought to examine the relationship between a retention program and the persistence and graduation rates of first generation, low-income students enrolled in the program, thus chapter 2 comprises a review of the literature on persistence and retention, with a primary focus on first-generation college students, which includes work by Astin, (1993), Gardner, (1996), Pascarella and Terenzini (1998), Pratt and Skaggs (1989), Strage, (1999), Tinto, (1998), and Warburton, Bugarin and Nunez (2001). Chapter 3 outlines the methodology used in the study including a description of the rationale of the sample, the data collection procedure, and the methods of analysis of data. The findings of the study are presented in Chapter 4, and Chapter5 offers the reader a discussion of the findings, conclusions, and recommendations. 


\section{CHAPTER II}

\section{LITERATURE REVIEW}

First-generation, low-income students often face compounding challenges imposed by conflicting obligations, false expectations, lack of preparation, and lack of academic or social support, factors that may hinder their progress and lead to their dropping out (Choy, 2001; Terenzini, Springer, Yaeger, Pascarella, \& Nora, 1996; Tinto, 1975, 1987). Similarly, Adelman's (1999) research with the National Education Longitudinal Study (NELS) national student sample found academic preparation and rigor were very strong predictors of college student retention. Students with weak academic preparation were much more likely to withdraw than students who had taken a rigorous set of college preparatory courses in high school.

Since Tinto's (1975) academic and social integration model served as the basic theoretical foundation of this dissertation and the program intervention studied, an explanation of the major precepts of his longitudinal study are provided. Tinto identified the following background characteristics as important to persistence: family background, individual attributes, initial commitments, academic integration, and social integration. :

\section{Background Characteristics}

Tinto (1993) states that students enter postsecondary institutions with certain background characteristics such as family background, skills, abilities, and pre-college schooling that influence their levels of commitment to degree completion. He also suggested that students' level of commitment were continually shaped by their levels of academic and social integration within the college environment. According to Tinto, the 
more students are integrated socially and academically to the institution, the greater their commitment to degree completion.

\section{Academic Integration}

Tinto (1975) explained that every college and university has an ingrained academic and social system and students enter with their own ingrained characteristics. The match between these two is the level of academic integration. The academic system is determined by the student's grade performance and intellectual development.

\section{Family Background}

These are generally considered to be measured by attributes such as the parents' combined level of education, family income, and overall socio-economic status. Tinto (1975) asserted, "Children from lower status families exhibit higher rates of dropout than do children of higher status families even when intelligence has been taken into account" (p.99).

\section{Goal Commitment}

As explained by Tinto (1975), once the individual's ability is taken into account, it is his/her commitment to the goal of college completion that is most influential in determining college persistence. Commitment can be both general degree completion and commitment to earn that degree at the selected institution.

\section{Individual Attribute}

Tinto (1975) describes these as pre-entry attributes that include pre-college schooling, aptitude, and ability attributes. 


\section{Social Integration}

Tinto's (1993) Student Departure Model states that a student's decision to persist or withdraw may also be substantially influenced by his/her level of social integration in the college. Social integration is defined by the level of peer-group interactions and faculty/staff interactions of a social rather than academic nature. As with academic integration, the match between the individual student's attributes and the social milieu of the institution determines the level of social integration. These factors taken together may lead to incorporation into the college community or lead to permanent departure from the higher education setting.

Factors mentioned in the model, (Tinto (1975)that negatively affect social integration and lead to withdrawal decisions include parental and family pressures, the lack of integration between institutional types and individual preferences, and in some cases students' feeling of being overwhelmed by the mismatch with a large public institution. Factors that positively affect social integration and increase retention include involvement in campus activities, developing meaningful relationship with peers, adjustment to the institutional culture, and developing a sense of belonging. A sufficient level of academic and social integration is theorized as necessary for student persistence.

\section{Other Studies on Non-traditional First Generation Students}

Various studies on college students in general, and first-generation students in particular, have provided empirical support for Tinto's (1975) theory as well as this study. Tinto and others (e.g., Nora \& Cabrera, 1996)tested this theoretical framework empirically and found general support for the theory with a few exceptions. Empirical support is clearer with mainstream students. Critics of Tinto's model suggested that the 
model overemphasizes the role of the student in the departure process, leaving institutions the possibility of blaming students for their own failure and not examining the institutions' own responsibility (Yorke, 1999). Another criticism is that it underestimates the choices made by students in making decisions about leaving college (Stage \& Hossler, 2000). Braxton also suggested that the role of academic integration is not well supported empirically (Braxton \& Lien, 2000). Others have criticized the theory for being too ethnocentric (Rendon, Jalamo, \& Nora, 2000) or culturally normative (Tierney, 2000) in its assumptions.

Tierney (1992) suggested Tinto's (1975) model relied on information only about traditional students. Tierney (1992) also suggested that Tinto misrepresented Van Gennep's (1960) anthropological rites of passages and that this misinterpretation may "hold potentially harmful consequences for racial and ethnic minorities" (p.603). Rites of passage are movements from one level to another within the same culture, but for many ethnic minority students, the move to higher education is not a continuation within a culture but a movement between cultures, meaning that they remain a part of the culture from which they come, as well as integrate into the new culture of the college. Tierney noted Tinto's theory is too broad in its treatment of social integration and does not address specific examples that could be related to non-traditional students within higher education. For example, references to departure from society, such as a college or university, may have different contextual meanings for different groups, (e.g., Native Americans). Native American students who enter traditional colleges and universities undergo their own form of rite of passage. These students experience a "disruptive cultural experience not because college is a rite of passage, but because the institution is 
culturally distinct" from their culture of origin (Tierney, 1992, p.608).This description of the transition as disruptive may be appropriate for first-generation and low-income students as well and because of the various intervention strategies described in this study, students are assisted in navigating this new culture.

Tinto (1993) stated student departure is "value-neutral" (p.113), but Tierney (1992) asserted that the anthropological foundation associated with this concept does not apply to all individuals in all settings. Tierney's exception to the inclusion of the term departure suggested Tinto's limited understanding and appreciation of the minority students present in American higher education and how these groups tend to be alienated by the mainstream identity. Tinto recognized specific segments of the student population were ignored, including adults and students attending non-residential campuses. In more recent years, Tinto (1987) has acknowledged some of these criticisms as valid. Despite these criticisms and revisions by Tinto himself and others, his work has remained the dominant sociological theory of how students navigate through and potentially out of our postsecondary system.

\section{First Generation Students' Characteristics and Challenges}

In a study examining a number of the factors Tinto identified along with others, Somers, Woodhouse, and Cofer (2004) examined the relationship of background, aspirations, prior achievement, college experiences, and the price of college on the persistence of first-generation and continuing-generation college students at 4-year institutions. They discovered that some variables traditionally associated with college success were either not significant or had small effect sizes for first-generation students. Yet some patterns were consistent. For the background variables (parents' education 
level, age, race, and income), low-income and multiethnic first-generation students were less likely to persist. As expected, it was shown that seniors were much more likely to persist than first-year students. The researchers also found that first-generation students were the most aversive to debt.

In a study done by Nauman, Bandalos, and Gutkin (2003) to determine the predictive validity of self-regulated learning variables (intrinsic goal orientation, task values, expectancy for success beliefs, control beliefs, self-efficacy, study strategies, goal setting, seeking assistance from others, and time management) in comparison to traditional college admissions test scores (ACT) in first-generation students, the variable of expectancy beliefs was the most significant predictor of college grade point average followed by the ACT score. However, for the second-generation students, the ACT score was the most significant predictor followed by expectancy for success and then goal setting. For both generational groups, ACT score and at least one of the self-regulated learning variables significantly predicted GPA. Overall, $50 \%$ of the variance in GPA was predicted by the two significant variables (expectancy for success and ACT score) for the first-generation students and $31 \%$ of the variance in GPA was predicted by three variables (ACT score, expectancy for success, and goal setting) for second-generation students. In addition, while the ACT provided a significant amount of information about college GPA for both generational groups, self-regulated learning variables improved the prediction and, for first-generation students, this additional prediction far exceeds how well the ACT predicts college GPA.

In a study using data from the National Center for Educational Statistics (NCES) (1995-1996) on retention and graduation rates of Hispanics and first-generation students, 
Harrell and Forney (2003) reported that a little over half of first-generation students beginning college with the Core New Basic Curriculum (4 years of English, 3 years of mathematics, and 3 years of science and social studies) obtained a bachelor's degree. However, $81 \%$ of first-generation students who took the more rigorous high school curriculum (Core New Basic Curriculum plus biology, chemistry, and physics, 4 years of math, including algebra I, geometry, algebra II, precalculus, 3 years of foreign language, and one honors/Advanced Placement course) completed a bachelor's degree. Yet, the authors stated that first-generation students, compared to students with parents who were college graduates, were much less likely to have calculus in high school $(20 \%$ vs. $34 \%)$, which placed them at a disadvantage from the beginning of their college career. They further showed that $38 \%$ of first-generation students scoring in the lowest quartile on college entrance examinations would take one or more remedial courses upon admission to a postsecondary institution.

Harrell and Forney (2003) concluded that on average, students whose parents have a bachelor's degree compared to first-generation students have higher SAT/ACT scores, take more rigorous high school coursework, have a higher GPA, enjoy a higher family income, take less remedial coursework their first year in college, are more likely to be continuously enrolled while working toward a bachelor's degree and are less involved in part-time or full-time work outside of school.

Studies have shown a strong correlation between students' finances and their persistence. For example, Bean and Metzner (1985) and Cabrera, Nora, and Castaneda (1992) have argued that students' concerns with finances, along with other external factors to the institution, can affect their academic integration by increasing anxieties 
associated with the need to securing resources to finance their college education and by limiting the amount of time spent on academic activities. These researchers also cited the effect that finances have on the social integration by increasing or reducing students' barriers to full participation in the social component of the institution. However, for the purpose of this study financial aid was not studied as a factor on persistence because the students in the study were all low-income students.

To further support the research on retention of first generation students, Ishitani (2003) investigated the longitudinal effects on attrition between first generation students and their counterparts, after controlling for other factors such as race, gender, GPA, and family income. The focal point of this study was to examine whether the effects of independent variables hypothesized to influence student departure behavior varied at different points of a student's academic career. The study utilized a sample cohort of 1,747 college students who matriculated in the fall of 1995 at a 4-year comprehensive public university in the Midwest. Their attrition rates were studied over a period of 5 academic years, and Ishitani tracked the fall and spring semester enrollment status. Attrition was defined in this study as a student's first spell of departure from the institution, which included dropouts, transfers, academic dismissals, and stopouts. Approximately $58 \%$ of the students were classified as first generation. About $16 \%$ had two college-educated parents, and $26 \%$ had at least one parent who graduated from college.

The results of the study indicated that first-generation students were more likely to depart than their peers (Ishitani, 2003). The relative risk of departure of firstgeneration students in the first year was $71 \%$ higher than for students with two college- 
educated parents. However, the risk of departure among first-generation students was less pronounced in the third year and statistically insignificant in the second, fourth, and fifth years.

In a study using data from the NCES Beginning Postsecondary Students Longitudinal Study, 90/92/94, Hahs-Vaughn (2004) investigated the differences in firstgeneration and non-first-generation students' experiences surrounding their educational outcomes to determine what, if any relationship parents' education has on the collegegoing process. The investigation included pre-collegiate traits, curricular patterns, inclass experiences, out-of-class experiences, institutional contextual perceptions, and learning outcomes of first-generation and non-first-generation first-time beginning traditional age students who were U.S. citizens and who were pursuing an associate's degree or higher over the time period from 1990 through 1994. The results indicated that for first-generation students, college experiences had a stronger influence on educational outcomes than were pre-collegiate traits. However, for non-first-generation students, precollegiate traits were a stronger influence on what the students do in college and on what happens 4 years later. This suggests a need to further examine the relationship of college interventions. Further results of the study indicated that first-generation students differed from non-first-generation students on expected highest level of education, entrance exam score, nonacademic experiences, and aspirations for education. Limiting this study to only U.S. citizens restricts its applicability to a very diverse population.

In another study conducted by Pascarella et al. (2004), longitudinal data from 18 four-year colleges were analyzed to better understand differences between firstgeneration and other college students in the experiences and outcomes of postsecondary 
education. The analyses compared first-generation students with two other groups: students whose parents had both completed a bachelor's degree or above and students having one or more parents who had completed at least some college, but no more than one parent who had attained a bachelor's degree or above. Some of the influences studied included precollege academic preparation, parental income, educational aspirations, academic motivation, secondary school grades, race, and gender. The findings suggested that the level of parental postsecondary education had a significant influence on the academic selectivity of the institution a student attends, the nature of the academic and nonacademic experiences one has during college, and to some extent, the cognitive and non-cognitive outcomes of college. The study also revealed that first generation students completed significantly fewer credit hours across the 3 years of the study and worked significantly more hours per week than did the high parent education group. They were also less likely to live on campus than other students. Moreover, the additional responsibilities of work by first generation students might explain the fact despite a lighter academic load, first generation students had significantly lower academic grades than similar students whose parents were both college graduates. An important finding in this study was level of engagement with their institution's social and peer network by first generation students. For example, extracurricular involvement had stronger positive effects on critical thinking, degree plans, sense of control over their own academic success, and preference for higher-order cognitive tasks for first-generation than for other students. On the other hand, not all college experiences proved to be beneficial for first-generation students. For example, volunteer work, employment, and 
participation in intercollegiate athletics all tended to have a more negative relationship on first generation students than on non-first generation students.

Ting (1998) looked at precollege attributes that predict success of first generation and low- income students. He studied the relationship of two cognitive and eight psychosocial variables in predicting academic progress in the freshman year. These students were enrolled in a Student Support Services program at the university where the model considered high school rank and ACT scores as well as eight psychosocial variables. The psychosocial variables were positive self-concept, realistic self-appraisal system, coping with racism, availability of a strong support person, a preference of long range goals, demonstrated community services, successful leadership experience, and acquired knowledge in a field, and they were used to predict grade point average and academic progress in the freshman year. The non-cognitive questionnaire designed by Tracey and Sedlacek (1984) was used and utilized eight psychosocial variables to explain admission decisions and student attrition. In this study cognitive variables were students' high school class rank and ACT composite scores. First generation students were the first ones to attend college in their families, including their parents, and academic progress is defined as the academic units obtained at the end of the first year.

High school rank and successful leadership experience were found to be the strongest indictors of GPAs for first generation and low-income students (Ting, 1998). High school rank accounted for $34 \%$ of the variance in the first semester GPA. In the second semester, high school rank, successful leadership experience, and demonstrated community services were found to be effective indicators for GPAs. Cognitive variables, in combination with psychosocial predictors, accounted for $48 \%$ of the explained 
variance in GPA, higher than the variance for the first semester. The ACT composite score was not found to be a significant predictor.

The majority of these studies focused on aspects of the first- generation students experience outside the universities' control. Further, most compared first-generation students to their peers with more educated parents. As comparison studies, none of these first generation studies differentiated interventions that institutions could undertake or practices that differentiated among first generation students in persistence. These studies suggest that future research should focus on the first year of college and intervention within the university's control while statistically controlling for the individual student variables consistently shown to be related to persistence from this prior research. These include family income, parent education, and high school preparation. This study accounted for a number of the important factors identified in the prior studies. For instance, by defining the samples as underprepared, first- generation, low-income students, I accounted for these variations. Further, the ethnic makeup of these samples was less diverse than of the sample in the present study.

\section{Studies on Minority Students}

A look at the minority student retention literature is essential because Tinto's (1975) model of student persistence is the basis of this study and the various criticisms of this theory related to minority students.. Ethnicity is also significant because this study was conducted at a minority-majority institution that is classified as a HSI. Some of the prior research was conducted at specific institutions such as Historically Black Colleges and Universities (HBCUs), PWIs, and HSIs. 
Academic integration and preparation are primary features of many models of retention. Several studies have identified the academic deficiencies among many minority students and point to the inability of the school system to better serve underrepresented students (Astin, 1982; Fullilove \& Treisman, 1990). They attributed much of the poor preparation of minority students to the poor quality of elementary and secondary education in high-minority schools. Research shows that between 30 and $40 \%$ of all entering freshman are unprepared for college-level reading and writing (Moore \&Carpenter, 1985). Approximately $44 \%$ of all college students who complete a 2 or $4-$ year degree enrolled in at least one remedial course in math, writing, or reading (U.S. Department of Education, 2001a, p.49). Without the necessary skills needed to survive the rigorous programs at most colleges, many students underachieve and leave college during their freshman year or before their sophomore year begins (Astin, 1975; Tinto, 1975).

A study of the National Assessment of Educational Progress (NAEP) science scores of 17-year-olds emphasized the lack of higher-order skills (Association of American Medical Colleges, 1992). The study found that although 9\% of White students had the ability to integrate specialized scientific information, only $0.5 \%$ of African Americans and $1 \%$ of Hispanic students demonstrated this ability. Further exacerbating this issue is the false perception that minority students cannot succeed in these higherorder learning. Bean (1985) found that teachers who thought this way about minority students were more likely to send negative messages to their students regarding their ability in math or science. 
Many minority students are not only unprepared for the academic challenges, but the nonacademic ones as well (Hall, 1999; Tracey \& Sedlacek, 1985). They often experience culture shock, lack of diversity among students, faculty, staff, and curriculum that often restricts the nature and quality of minority students' interactions inside and outside the classroom, threatening their academic performance and social experiences. Qualitative data on African Americans who attend PWIs suggest the availability of ethnic and cultural organizations and a "critical mass" of African American students helps reduce the isolation and alienation often found on predominantly white campuses (Hall, 1999). Also, Tracey and Sedlacek (1985) argue that non-cognitive factors like selfconcept, an understanding of racism, and the ability to use coping mechanisms can have a positive effect on students' academic performance and persistence in college.

The research literature shows that HBCUs support campus climates that foster African American students' self-pride and confidence and lead to academic and social success. Although most African Americans at HBCUs do not experience culture shock associated with race, they do experience the culture shock of transitioning from a secondary educational system to a higher educational one. These institutions traditionally have used holistic approaches for developing students intellectually and socially including precollege outreach programs and extensive academic and career counseling (Reyes, 1997). These interventions explain why HBCU students demonstrate higher levels of psychosocial adjustment, academic gains, and greater cultural awareness than their counterparts at PWIs, despite any academic and economic difficulties (Himelhock, Nichols, Ball, \&Black, 1997). 
Researchers argue that the biased practices of many PWIs contribute to minority students' cultural shock and alienation (Ancis, Sedlacek, \& Mohr, 2000; Just, 1999; Lui \& Lui, 2000 Just (1999) argues that racial climate influences almost every aspect of minority students' college experience, leading to academic and social marginalization. Lui and Liu (2000) characterize the alienation of minority students on PWI campuses as a structural rather than an individual issue, making colleges and society in general partially responsible for these minority students' lack of college persistence. Ancis et al. (2000) found that African Americans and Asians perceived and experienced greater pressure to conform to stereotypes, and they had less favorable interactions with faculty and staff at PWIs.

For underrepresented minorities in universities, contact with positive role models is even more significant than it is for majority students, perhaps because the larger society provides few rewards or does not reward minorities in the same way. A study of a mentoring program at Ohio University in Athens, Ohio, found that $91 \%$ of the African American protégés felt more confident as a result of their mentor (Ugbah \& Williams, 1989). This supports Tinto's (1993) theory that interaction with faculty not only increases social integration and therefore institutional commitment, but also increases the individual's academic integration.

In his study on persistence of 24 African American students (13 males and 11 females) at four, small predominantly white community colleges in the Southeastern United States, Littleton (2001) found seven emerging themes students identified to explain their persistence: Approachable and caring faculty, Black spokesperson (someone from the same ethnic background who serves as an advocate), African American role 
models, stereotypes, environmental appeal, students as sojourners (students feeling as if they are in a foreign land), and minority within a minority. Seventy-one percent of the students felt that faculty influence was a persistence factor. Some mentioned the need for African American faculty or administrators (other than coaches) to serve as role models at their institutions. The importance of the college environment was also a persistence factor, with $42 \%$ agreeing that their college was a quiet place with few distractions.

\section{First Generation Students’ Needs}

The need to provide services that increase the retention of first generation students is further supported from a study by Terenzini, Rendon, Upcraft, Millar, Allison, Gregg \& Jalamo (1994) that sought to discover: (a) the social, academic, and administrative mechanisms that foster students' involvement in the academic and social systems of the their institutions, (b) processes involved in the transition from high school or work to college, (c) the important people who facilitate or impede this process, (d) the experiences that play a major positive or negative role in the success or failure of that transition, and (e) the nature of the transition process for different kinds of students or for similar students entering different kinds of institutions. The results of the study, conducted primarily through interviews and focus groups, showed there was a relationship between various variables, such as students' social, family, and educational background, with the transition process to college. For first generation students, the study found that the transition was far more difficult and for many constituted a major dysfunction in their life course. Contrary to multi-generation students, first-generation students appeared to be breaking, not continuing, family tradition and the process often involve academic, social, and cultural transitions. To summarize the major themes in the 
study were (a) college was seen as a natural continuation for traditional students, (b) college was seen as a disruption by first generation students, (c) high school friends and family were either assets or liabilities to their transition, and (d) validating students' experiences was important. Yet no interventions or services offered by the college were tested.

Bui (2002) studied first generation versus non-first generation college students who were enrolled in the Program Leading to Undergraduate Success at University of California, Los Angeles (UCLA) specifically examining their reasons for pursuing higher education and the differences in their first year college experiences. He found that first generation students gave different reasons for attending college when compared to nonfirst generation students. Some of their reasons included the desire to gain respect, bringing honor to their families, and helping out their families financially compared to reasons such as their parents or other siblings went to college and the desire to move out of their parents' home by non-first generation students. In terms of their first year experiences, first generation students were more concerned about failing and worried about financial aid in comparison to other students. They also reported knowing less about the social environment at the university than did the non first generation students and having to put more time into studying than the comparison groups.

Pike and Kuh (2005) in their national study of 3000 undergraduates who completed the College Student Experiences Questionnaire sought to address three questions: (a) Are the relationships among background characteristics, engagement, and learning and intellectual development the same for first- and second generation students? (b) Do first and second generation college students differ in terms of their backgrounds, 
level of engagement during college, and reported gains in learning and intellectual development? and (c) Are differences between first and second generation students directly related to first generation status, or are they an indirect result of the associations between first generation status and antecedent characteristics or experiences?

The results from that study indicated that on some key indicators of college success, first-generation college students do not compare favorably with their peers from families where at least one parent graduated from college (Pike \& Kuh, 2005). Specifically, first generation students were less engaged overall and less likely to successfully integrate diverse college experiences; they perceived the college environment as less supportive and reported making less progress in their learning and intellectual development. Most of these differences, according to the study, resulted because of educational aspirations and where students lived when attending college. The study also indicated that female minority students who planned to pursue an advanced degree and students living on campus tended to be more engaged overall and had greater gains in their learning and intellectual development. Pike and Kuh did not report any findings related to specific college interventions.

In a study to explore the nature of college readiness from the perspectives of first generation college students, MacDonald (2005) studied eight undergraduates from a small urban university in the Pacific Northwest who transferred from a community college, were over 25 years old, and first generation. Through interviews, data about participants' backgrounds and experiences were gathered. In addition to recognized academic skills, participants indicated that skills in time management, the ability to apply oneself and focus on a goal, and skills for advocating for oneself as a learner were 
essential for college readiness. Knowledge of the college system and having personal support were also mentioned as important factors for success in college. All participants reported that they lacked sufficient guidance and support from family or high school counselors to help prepare them for understanding the college system. Also, awareness of financial aid availability was an area in which participants felt particularly unprepared. One distinctive finding of their study was that first generation students' life experiences contributed to the development of skills perceived as critical to success in college. Their work experiences and family motivations gave students the time management, goal focus, and self-advocacy skills that prepared them for the demands of college. Another distinctive implication of this study was that younger first generation college students might be at risk for college readiness, given that life experience and being older contributed to the skills of older first generation students. Again this study did not examine any campus interventions.

Inman and Mayes (1999) also investigated whether first generation community college students differed from other community college students, in what ways were they different, and to what extent these differences relationship their success. Their study involved 5057 entering students in the University of Kentucky Community College System with $91.4 \%$ indicating that they were first-generation students. Through a survey and data from student records, three areas of differences were examined: the demographic profile; goals and motivations; and academic intentions and early academic performance. In terms of their demographics, first-generation students were different than non firsts in some ways. Firsts were more likely to be female, more likely to be older, have fewer people in their households, and had more financial dependents. Firsts 
were more likely to have a slightly higher personal income, but more likely to have lower family incomes and work slightly more. On questions concerning motivating factors, two general issues seemed more important for firsts than non firsts. One was geographic and financial constraints and the greater importance they place on not being able to leave home, needing a college near to home, and seeking night courses probably because of the importance of keeping their jobs. Firsts were more motivated to learn certain knowledge and considered the reputation of the college for good teaching to be more critical than non-firsts. In terms of actual performance, this study showed that first generation students were equally able to succeed and did not view the community college experience as an opportunity to merely rectify a poor academic record from high school as many non-firsts reported.

These studies often identified a broader set of characteristics and needs of first generation students than the earlier comparison studies. Yet, the one thing all these studies have in common is their failure to examine the effects of campus services. We have a relatively good understanding of the differences between first- and non-firstgeneration students and the needs of first-generation students, but very little research has been conducted to test interventions to serve these students.

\section{Research on Program Interventions in General}

Research on learning communities supports Tinto's (1987) theoretical framework on student retention. The learning community model of academic and social integration increases students' connection with the college in general and with the learning process specifically. Taylor, Moore, Macgregor, and Lindblad (2003) reviewed 32 formal research studies and 119 single-institution assessment reports on learning communities 
that resulted in some major findings. Learning communities strengthen student retention and academic achievement. Both teachers and students found their learning community experience positive. Learning communities are effective in many areas including programs for entering students, general education coursework, and living/learning communities. Yet, few of these studies included substantial numbers of diverse students as the students represented in my study.

In one study by Kadel, Russo, \& Tinto (1995), 70 students enrolled in an interdisciplinary, team-taught coordinated studies program at an urban central community college were interviewed. Russo identified three dimensions of the student experience that learning communities needed to address: struggles to attend college, struggles to participate actively in the classroom, and struggles to understand an unfamiliar paradigm for learning that valued their own knowledge construction. Russo found that students believed the learning communities played an important role in helping students make connections across disciplines, with peers, and between the knowledge and values they brought to college and their classroom experiences.

Tinto, Russo, and Kadel (1994) in a study on students in a learning community found that students who "participated in the learning community had better grades and were more involved with their peers both inside and outside the classroom than those who did not'( p. 34). This would be consistent with Tinto's (1987) model of academic and social integration being important to student persistence or departure. Tinto's sample involved White students attending 4-year residential colleges.

These studies demonstrated how learning communities benefit a mainstream population but did not examine their relationship on low-income, first-generation, 
academically under-prepared and ethnically diverse students. The cited studies are different from mine in that they primarily looked at the interaction between the students and the faculty members and building other social support around this relationship. Therefore, the unexplored relationships on campuses are profession staff and mentors and whether interaction with these individual has a similar, greater, or lesser relationship. While there are many general studies on mentoring, virtual no research has been done on the relationship of peer mentors for diverse students. Peer mentors were a key feature of the current intervention. My study looked at a staff-directed intervention that provides academic and social support to the students through tutoring, leadership, and cultural enrichment activities, although there is some collaboration with faculty.

Fidler and Godwin (1994) described the success of a freshman seminar course that was instituted in 1973 at the University of South Carolina and its success in the retention of African American students. The course was specifically constructed with the unique needs that this subpopulation brought to a predominantly White campus where they often felt lonely and alienated. African American members of the campus community were invited to do presentations to students and often they formed mentor relationships. These students also met with students from other cultures and formed friendships. As a result, over the 13years of the study, the retention rate to the sophomore year for African American students who took the course was higher compared to those who did not take the course.

\section{Research on Program Interventions for At-Risk Students}

Bridge programs are also shown to improve retention of non-traditional students which includes first- generation students, but there are few studies of campus 
interventions to improve student retention that meet the standards of rigor for publishable research (Braxton et al., 2006; Patton et al., 2006). One study done by McKenzie (2005) in Australia looked at attrition rates of Maori students in a bridge program designed to prepare students for postsecondary education. About a quarter of the 256 students were Maori, a quarter European, another quarter Pacifica, and the remainder comprised of primarily Asian or Indian. The institution developed a system (based on the feedback of students who felt overawed by the size of the campus) of "scaling down" to provide the students with places to meet and study together. Consistent with Richardson and Skinner (1992) these centers provided a way of building peer support networks. A center for Maori students was set up in 1998, and the Maori tutoring staff was increased to closer reflect the percentage of Maori students in the program. A system of monitoring students' success by one-on-one advising was also instituted, and increased follow-up procedures were put in place to monitor students in the program. Following the implementation of strategies that involved increased mentoring and building support networks were put in place, the attrition rate went from $46 \%$ in 1997 to under $35 \%$ by 1999. This figure falls closer in line with prior research. Tinto (1993), citing numerous studies on attrition, provided a figure of $30 \%$ as being a common dropout rate for all firstyear students. Yet, it is unclear whether these same intervention strategies would work with U.S. populations. The current study tested similar interventions for a diverse group of U.S. students.

A bridge program study carried out at The Ohio State University by Newman and Newman (1999) also demonstrated the importance of academic integration, financial support, mentoring, and social integration activities in increasing the retention rates of 
under-prepared, first generation minority students in some urban cities in Ohio. By establishing early contact with middle and high schools in some of the major cities in Ohio through the Young Scholars Program (YSP), students made an early connection to university faculty and students, as well as with community leaders, parents, and other participants in the program. Newman and Newman concluded students also benefited from on-campus precollege enrichment programs that provided YSP freshmen with a history of mastering challenging subjects, a sense of familiarity with the university environment, and a belief in their ability to succeed. Results of the program showed that in one group, after 2 years at The Ohio State University, the retention rate of YSP students was $72 \%$ compared to a matched comparison group whose 2 -year retention was $62 \%$. In the second group of YSP students, after 1 academic year their retention rate was $88 \%$ the same as that for the entire freshman class. The two comparison groups, one matched group and the other with similar characteristics as the matched group except for race, showed retention rates below that of the YSP students. This multi-year precollege program implements an integration strategy found to be effective in promoting retention.

Further empirical research on support services and programs involved a study done at a medium-sized Midwestern university that looked at the effect of The Freshmen Empowerment Program (FEP)on the persistence and academic performance of firstgeneration students who were enrolled in the program compared to a similar group who were not in the program (Carter, Chase, \& Folger, 2004). Of the 200 students who expressed interest in participating in the program, 53 were randomly selected and placed in FEP groups. The control group $(n=53)$ was drawn from the remaining 147 students. Quota sampling was used to insure the group would be equivalent to the FEP group in 
terms of ACT scores, gender, and ethnicity. Although the FEP and control groups were constructed to be equal in terms of ACT scores, gender, and ethnicity, these were not strictly groups of matched pairs. Therefore independent $t$-tests $(p=.05)$ were used to compare the outcomes of fall semester GPA, spring semester GPA, and cumulative freshman GPA of the FEP and control groups.

Group activities focused on community building activities with many participants forming friendship with other group members or using the groups as a support system (Carter, J.A., Chase, P.B., \& Folger, W.A., 2004). They were also provided with support services which included academic assistance, career counseling, social activities, and encouragement and information on connecting with faculty and on forming mentoring relationships. Results of the study indicated a first year retention rate of $79 \%$ for the FEP students compared to $39 \%$ for the comparison group. First generation students in the program also had a first semester GPA of 2.26, compared to 1.51 for the control group.

Carter J.A., Chase, P.B., \& Folger, W.A. (2004) study bears some similarity to this study because both focus on social interaction in a support system. However, the present study focused on a different population of first-generation students at a larger HSI. Specifically, this study examined a subgroup of first-generation students who are also low-income and academically underprepared. Second, their study used $t$-tests, and simple $t$ test analyses do not account for the multiple complex factors known to contribute to student persistence. Some of those factors they control for by matching the comparison groups to some extent, but they do not account for factors such as high school rank or grade point average. There were no studies that examined an intervention program for my population. There were some studies that looked at remedial or 
developmental coursework for underprepared students, but none that looked at an intervention designed around the theory of academic and social integration with services to meet those needs.

\section{Conclusion}

The benefits of a learning community to the general population have generally been established, but most of the research on underprepared, first-generation, low-income students has been on precollege programs. The few studies that look at campus interventions have been statistically less sophisticated or merit replication with a more ethnically diverse population at an HSI.

This study looked at the application of Tinto's (1975) theory of social and academic integration in a population of students facing multiple challenges to their success. Students in my treatment group were all participants in a retention program, and the group functioned as a learning community. It was believed participants developed closer relationships to each other, thus enriching the social interactions at the university. Control group students were similar demographically but did not receive these services. More importantly, participants in my study were first-generation, low-income, high percent minority, and under-prepared whereas participants in the cited studies came from the general student population.

Students in the study were academically less-prepared than multi-generation students and less likely to achieve as a result of compounding variables and identified challenges. Several studies describe their experiences and the challenges they face but did not test a campus intervention. Even those that tested an intervention are not the same as this study. This intervention was tested on an academically challenged, low- 
income population, and using regression allowed me to better separate out the effects of participation in the program and other strengths or barriers for these students. Finally, this study did not compare first to non first-generation student as many of the early studies did. The distinction between first and non-first-generation students is clear and has been described. This study tested an intervention that had not been rigorously tested with this population. Therefore, my unanswered research questions were:

RQ 1. Are there differences in persistence rates and other academic characteristics of underprepared, low-income, first generation college students who participate and do not participate in the retention program?

RQ 2. Does involvement in the retention program predict student persistence of first generation low-income, underprepared college students?

RQ 3. Can predictors of GPA be identified for students in the retention program using program and descriptive variables? 


\section{CHAPTER III}

\section{METHODS}

This quantitative study tested the relationship between participation in a treatment intervention on college persistence using logistic regression. The university received a grant from the U.S. Department of Education to establish a student support program aimed primarily at providing retention services for low-income, first-generation students by implementing strategies for coping with challenges to academic and social integration. This program emphasizes the content and strategies considered critical in the students' adjustment. Services to students include tutoring (individual and group), supplemental instruction, study skills training, leadership development, mentoring (peer and professional), career development, and cultural engagement activities.

\section{Research Design - Ex Post Facto}

An ex post facto research design can be defined as one where the independent variable has already occurred or cannot be manipulated (Newman\& Newman, 1994). My study utilized archival data to determine the relationship between program services on persistence and graduation rates of first-generation, low-income students who participated in the program from 1999-2006. This study tested academic and social integration theory (Tinto, 1975) based on knowledge from prior research and expectations of outcomes based on application of that theory to a new group of students. 


\section{Participants}

This study included 292 first-year students who all entered the university during the summer term and participated in the university's summer bridge program. This university is an urban, commuter, multi-campus, doctoral-granting HSI institution with a major research facility. The student body is very diverse, comprising 59\% Hispanics, 17\% White Non-Hispanics, 13\% African Americans, 4\% Asian or Pacific Islander, 7\%

other minority groups and 56\% female(University Website, 2008). The majority of the student body (60\%) is enrolled full-time and approximately $70 \%$ are between the ages of 17 and 25 . This racial/ethnic diversity of students adds to the generalizability of the study and addresses the critical void in research with wide variability in the sample.

Participants in the study were recruited during the summer and did not meet more rigid SAT/ACT and GPA fall admissions requirements. The comparison group with similar admissions characteristics also participated in the university's summer program as a shared starting point, however they did not participate in the retention program. This program was consistent across the full sample. The 126 participants in the treatment/retention program and 166 student comparison group were selected during 1999, based on three criteria: (a) first-generation, (b) low-income, and (c) academic under-preparation. First-generation status denotes that neither of their parents attained a bachelor's degree or higher. If students qualified for a Pell Grant, they were considered low income. Students qualify for federal Pell Grants based on family financial need. Nationally more than $90 \%$ of families receiving Pell assistance earn less than $\$ 35,000$ a year (http.//usliberals.about.com, "Pell grants defined \& updated for 2006”).The cohort 
year of 1999 was used because it allowed for the examination of persistence over a 6-year period with archival university data.

\section{Data}

Archived student record data for the years 2003 and 2006 were collected from the university's Office of Institutional Research including the persistence outcome variable and selection variables of high school GPA and SAT/ACT scores. The outcome variable was coded as 1 for persisted, meaning successful graduation or still enrolled, and 0 for students who withdrew within 4or 6 years (see Table 1). Descriptive data such as gender, ethnicity, and other demographic and academic variables were collected from the Office of Institutional Research. These data were also analyzed to check and adjust for possible confounding variables and interaction effects.

\section{Treatment}

Students in the treatment program received free tutoring in various areas such as college algebra, biology, statistics, essay critique, chemistry, pre-calculus, and calculus. Students received one-on-one as well as group tutoring. Participation in these services was voluntary for students who were making good academic progress, but mandatory if they were having academic difficulties in these areas. Typically more than $50 \%$ of the students take advantage of the tutoring available. On the average, students visited tutoring services at least twice a week during the fall semester. They also attended workshops, including those on time management, study skills, financial aid, and career development. These workshops were voluntary small group sessions, and about $85 \%$ of students chose to attend at least one session and $60 \%$ of participants chose to attend more than one. 
Table 1

Independent Variables and Their Coding in the Regression Model

\begin{tabular}{|c|c|c|}
\hline Variable & Coding & Notes about coding \\
\hline \multicolumn{3}{|c|}{ Participant variables } \\
\hline Gender & $\begin{array}{l}1 \text { male } \\
0 \text { female }\end{array}$ & $\begin{array}{l}\text { Cases with missing data } \\
\text { were included in the control } \\
\text { group. }\end{array}$ \\
\hline Ethnicity/race & $\begin{array}{l}\text { 0- Hispanic/Latino } \\
\text { 1- Black or African } \\
\text { American } \\
\text { 2- White } \\
\text { 3- American Indian or } \\
\text { Alaskan Native } \\
\text { 4- Asian } \\
\text { 5- Other }\end{array}$ & $\begin{array}{l}\text { Categories adapted from the } \\
\text { university's undergraduate } \\
\text { application form. }\end{array}$ \\
\hline College GPA & $\begin{array}{l}\text { Continuous variable with a } \\
\text { range from } 0 \text { to } 4.0\end{array}$ & \\
\hline Admissions test score & & $\begin{array}{l}\text { Students could submit SAT } \\
\text { or ACT admissions test } \\
\text { scores. Scores on the ACT } \\
\text { test were converted to the } \\
\text { SAT test values. }\end{array}$ \\
\hline Advising & $\begin{array}{l}\text { Program variables } \\
\text { Frequency }\end{array}$ & \\
\hline Social event & Frequency & \\
\hline Tutoring & Frequency & \\
\hline Workshops & Frequency & \\
\hline
\end{tabular}


Students who regularly attended workshops and utilized the academic services as well as demonstrated financial need received stipends ranging from $\$ 400$ - $\$ 800$ for the year. As part of their peer mentoring, students met with their peers at least biweekly. They also met with a staff member on a biweekly basis. Both the peer mentoring and the meeting with the staff member were required and had a high participation rate. These and other activities facilitated increased staff interaction with the students both individually and in smaller groups and thus enabled staff to catch an early signs of academic trouble or weak integration. Staff were from first-generation backgrounds or in other ways able to identify with the participants. Peer mentors were also selected on the basis of how well they had integrated in the college environment, both academically and socially. There were three full-time equivalent staff members, so each staff member worked with approximately 50 students. Tutors were selected based on their GPA and particularly on the grade they received in the subject area that they were hired to tutor. Priority was given to students who were from low-income and first generation backgrounds or students who had a passion to work with students from these backgrounds. As level of engagement in the program differed among the students, the degree of their engagement had to be treated as a covariate. The operational definition of this covariate was $0=$ below average engagement; $1=$ average engagement, and $2=$ above average engagement. A count was kept in office records of how often students participated in the services over the course of their first year in school. A total participation score was created by summing across attendance at each service provided by the retention program. 


\section{Data Analysis}

Persistence as a dichotomous variable was compared for participants in the retention program and non-participants descriptively and using logistic regression to identify whether participation significantly predicted persistence while covarying several variables known to be associated with persistence such as GPA and SAT/ACT score. The key predictor variable was participation in the retention program and the criterion variable was retention/persistence. It was hypothesized that students who participate in this program would be retained at a higher rate than students who did not. 


\section{CHAPTER IV}

\section{RESULTS}

Chapter 4 presents the analysis of the data collected for the study to address the three research questions posed by the study. The purpose of the study was to examine differences in persistence rates and academic characteristics and identify whether or not variables indicating participation in a retention program predicted persistence or graduation for a group of underprepared, first generation, low-income students at a multiethnic university. Also, it examined whether predictors of GPA could be identified for students in the retention program using program and descriptive variables. The chapter restates the research questions posed for the study followed by a discussion of the participants in the study. The three research questions and the analysis for each question are presented with the findings of the analysis, the chapter closes with a summary and introduction to Chapter 5. The research questions posed for the study are as follows:

RQ1: Are there differences in persistence rates and other academic characteristics of underprepared, low-income, first-generation college students who participate and do not participate in the retention program?

RQ2: To what extent does involvement in the retention program predict persistence of first-generation college students?

RQ3: Can predictors of GPA be identified for students in the retention program using program and descriptive variables? 


\section{Study Participants}

A total of 292 students considered under-prepared for higher education, lowincome, and first generation college students were identified for the study. All of the students were enrolled in a university summer bridge program during 1999. A group of 166 students (56.8\%) were selected for a comparison group because they had not participated in the within-year retention program, and 126 students (43.2\%) voluntarily participated in the retention program before this study was conducted. There were originally 160 students in the sample, but after review, 28 students had a different enrollment date and had to be dropped from the sample. Persistence (continuing to enroll toward a degree) or graduation status was determined for all students from university archival records by 2006 . The term graduated was used to designate students' persisting to complete a degree by continuing to be enrolled or graduating with a degree. Not graduating was used to designate all students who did not graduate and withdrew from the university.

The students were compared to determine persistence or graduation and not graduating by summer 2006.A higher percentage of students in the retention program had graduated $(n=82,65.1 \%)$ than in the comparison group $(n=79,46.6 \%)$. Table 2 presents the data for graduation by group. 
Table 2

Non Participants and Participants in Retention Program by Graduation

\begin{tabular}{lcccc}
\hline Graduated/Not graduated & \multicolumn{2}{c}{ Non participants } & \multicolumn{2}{c}{ Participants } \\
& $n$ & $\%$ & $n$ & $\%$ \\
\hline Not graduated & 87 & 52.4 & 44 & 34.9 \\
Graduated & 79 & 46.6 & 82 & 65.1 \\
\hline
\end{tabular}

Of the 292 study participants, 206 (70.5\%) were women and $86(29.5 \%)$ were men. There were more women in the retention program $(85.7 \%)$ and the control group $(59.0 \%)$ than there were men; however, there were more men in the control group $(41.0 \%)$ than there were in the retention program (14.3\%; see Table 3$)$. Chi square analysis indicated statistically significant differences between the observed and expected frequencies, $X^{2}(1)=24.536, p=<.001$. It should be noted that eligible students had to voluntarily apply to be accepted into the retention program, and these results indicated that females were more likely to seek assistance than males.

Table 3

Non Participants and Participants in the Retention Program by Gender

\begin{tabular}{lcccc}
\hline Gender & \multicolumn{2}{c}{ Non- participants } & \multicolumn{2}{c}{ Participants } \\
& $n$ & $\%$ & $n$ & $\%$ \\
\hline Female & 98 & 59.0 & 108 & 85.7 \\
Male & 68 & 41.0 & 18 & 14.3 \\
\hline
\end{tabular}


The participants and non-participants in the retention program represented 5 racial/ethnic groups including: Asian $(n=9,3.1 \%)$, African American $(n=94,32.5 \%)$, Hispanic $(n=145,50.2 \%)$, Caucasian $(n=34,12.1 \%)$, and other $(n=6,2.1 \%)$. Table 4 presents the breakdown of racial/ethnic identification by participants or non-participants in the program. The largest minority group was Hispanics with $49(39.8 \%)$ in the participant group and $96(57.8 \%)$ in the non-participant group. This was followed by African Americans and Caucasians. However, the students were not equally distributed by ethnic group between those who participated and those who did not participate in the program. African American students were more likely to participate in the retention program than any other racial/ethnic group. White students and those classified as other were least likely to participate in the program.

Table 4

Non-Participants and Participants in the Retention Program by Ethnic/Racial Identification

\begin{tabular}{lcccc}
\hline Racial/Ethnic Background & \multicolumn{2}{c}{ Non-participants } & \multicolumn{2}{c}{ Participants } \\
& $n$ & $\%$ & $n$ & $\%$ \\
\hline Asian & 5 & 3.0 & 4 & 3.3 \\
African American & 25 & 15.1 & 69 & 56.1 \\
Hispanic & 96 & 57.8 & 49 & 39.8 \\
Caucasian & 34 & 20.5 & 1 & .8 \\
Other & 6 & 3.6 & 0 & 0.0 \\
\hline
\end{tabular}




\section{Retention Program Descriptive Data}

Students participating in the retention program had a number of services available to them including: social events, tutoring, workshops, and advising. A count was kept in office records of how often students participated in the services over the course of their first year in school. A total participation score was created by summing across attendance at each service provided by the retention program. Retention program students attended between 0 and 2 social events $(M=1.32, S D=0.776)$ and attended between 0 and 8 workshops $(M=3.85, S D=1.842)$. Tutoring was available for students making good academic progress and mandatory for students having academic difficulties. Assistance was available for subjects such as college algebra, biology, statistics, essay critique, chemistry, pre-calculus, and calculus and was available for groups and on an individual basis. Students in the retention program attended between 0 and 10 tutoring sessions $(M=4.10, S D=1.895)$. Students also attended between 1 and 12 advising sessions $(M=5.73, S D=2.844)$. Overall, retention program students attended between 2 and 32 retention program events $(M=14.99, S D=6.534)$. 
Table 5

Descriptive Statistics for Participants in the Retention Program

\begin{tabular}{lccccc}
\hline Program Features & $n$ & Min. & Max. & $M$ & SD \\
\hline Social event & 126 & 0 & 2 & 1.32 & .776 \\
Tutoring & 126 & 0 & 10 & 4.10 & 1.895 \\
Workshops & 126 & 1 & 8 & 3.85 & 1.842 \\
Advising & 126 & 1 & 12 & 5.73 & 2.844 \\
Total participation & 126 & 2 & 27 & 14.99 & 6.534 \\
& & & & & \\
\hline
\end{tabular}

\section{Findings for the Research Questions}

\section{Research Question 1}

Are there differences in persistence rates and other academic characteristics of underprepared, low-income, first generation college students who participate and do not participate in the retention program?

The null or statistical hypothesis was as follows:

$\mathrm{Ho}_{1}$ : There will be no differences in academic achievement (college grade point average and SAT scores) for students participating in a university retention program and students not participating in a university retention program. Analysis of variance was used to test for differences between the means of the two groups using a significance level of $p=.05$ or less for accepting or rejecting the null hypothesis. The Levene test for homogeneity of variance indicated for SAT scores $(p=<.001)$ the assumption of homogeneity of variance was not met. However, the Levene test for grade point average 
( $p=.064)$ was marginal. Mertler and Vannatta (2001) note the Levene test tends to be conservative, and ANOVA is also a robust statistical procedure that tolerates some violation of the assumptions. Histograms indicated the data were fairly normal.

Results of the analysis indicated there were statistically significant differences for SAT, $F(1,254)=11.771, p=.001$ and for college grade point average, $F(1,290)=$ $10.171, p=.002$. The null hypothesis was rejected for SAT and for grade point average. Inspection of the means for the retention program participants and non-participant groups indicated the non-participant group had a higher SAT score on average ( $M=909.94$, $S D=75.482)$ than did students in the retention program $(M=869.78, S D=110.72)$. However, on average retention program participants had a higher grade point average $(M=2.72, S D=.61)$ than did students not participating in the retention program $(M=2.47$, $S D=.67)$. It should be noted that students in the non-participant group had higher SAT scores than students in the participant group, which suggests that they were better academically prepared. However, students in the participant group had higher college GPA than students in the non-participant group suggesting participating in the retention program was positively associated with academic success.

$\mathrm{Ho}_{2}$ : There will be no differences in graduation rates between the students who participated in the program and those who did not participate.

A Chi square analysis indicated the differences between the observed and expected frequencies were statistically significant, $X^{2}(1)=8.857, p=.003$. Therefore, in a simple comparison, those students who participated in the retention program were more likely to graduate than those students who did not attend. This comparison shows that for low-income, first generation, academically underprepared students, participating in a 
retention program that included academic and social components was a positive predictor of graduation.

Considering participants in the program started with lower SAT scores, but yet had higher grade point averages and were more likely to graduate, there was a strong association between participation in the program and student achievement and attainment. Although this analysis showed that overall the program was associated with persistence, it did clarify what aspects of the program were associated with persistence. Further exploration could offer insights about what feature of the program may be associated with student success.

\section{Research Question 2}

To what extent does involvement in the retention program predict persistence of first-generation college students? The dependent or predicted variable for this analysis was dichotomous, graduated $=1$ and non-graduate $=0$, and a logistic regression was the appropriate statistical procedure. A probability level of $p=.05$ was used as the criteria for accepting or rejecting the null hypothesis. Logistic regression served to classify individuals into groups. In this study the purpose was to identify the independent predictor variables that predict graduation/persistence or not graduating/persisting for a group of low-income, first-generation, under-prepared university students participating in a retention program. The independent predictor variables were: GPA, gender, ethnicity, participating in social events, tutoring, workshops, and advising. Racial/Ethnic group was re-grouped into a dichotomous variable with Hispanic $=1$ and all other racial/ethnic groups $=0$. 
A forward Wald logistic regression was conducted to determine which independent variables were predictors of graduation/not graduating. Although it would have been interesting to consider all the program features (advising, workshops, etc.) simultaneously in one analysis, that was not possible because of the colliniarity between the independent program feature variables. In general there were high participators across events and low participators across events. Considering not all program feature variables were significant, they represented distinct constructs and not just participation.

The second research question asked whether or not predictors of college completion or persistence could be identified from program variables. These program feature analyses controlled for other variables known from prior research to be associated with persistence. The first program feature null hypothesis was as follows:

$\mathrm{Ho}_{3}$ : Attending tutoring sessions is not related to graduation.

Free academic tutoring was available to students in key first-year courses. This service was one of the most utilized by students. Students in academic difficulty were required to attend. This analysis tested whether tutoring was significantly associated with persistence. As shown in Table 6 below, attending tutoring sessions was significantly positively related to graduation while holding the control variables gender, ethnicity, and college GPA constant. Interestingly, for this sample, typical predictors like the control variables in this model were not always significant. The pseudo $\mathrm{R} 2$ is an estimate of the explained variance, therefore if the Cox and Snell R2 is .675, then approximately $68 \%$ of the variance is explained by the model. 
Table 6

Regression Coefficients for Retention Program Students (N=126)

\begin{tabular}{lcccccc}
\hline & $B$ & Wald & $d f$ & Sig & $\operatorname{Exp}(\mathrm{B})$ & $95 \%$ Confid Interval \\
\hline Tutoring & 6.619 & 5.484 & 1 & .019 & 749.141 & $2.943,190698.43$ \\
Gender & 4.796 & 1.893 & 1 & .169 & 120.998 & $.131,112059.06$ \\
Ethnicity & -1.906 & 1.277 & 1 & .258 & .149 & $.005,4.052$ \\
GPA & 7.023 & 3.810 & 1 & .051 & 1121.798 & $.971,1295675.6$ \\
Constant & -44.268 & 4.328 & 1 & .037 & .000 & \\
\hline
\end{tabular}

Cox \& Snell R Square $=.675$

The retention program also offered voluntary workshops for students. Workshops were conducted on topics such as study skills, time management, career development, and leadership development. At least one third of retention program participants took advantage of these workshops.

Ho4: Attending workshop sessions is not related to graduation.

Table 7 shows that attending program workshops was significantly and positively related to graduation while holding the control variables of gender, ethnicity, and college GPA constant. Therefore, among retention program participants, those who attended the workshops were more likely to graduate. The pseudo R2 is an estimate of the explained variance, therefore in the Cox and Snell R2 is .665, then approximately $67 \%$ of the variance is explained by the model. 
Table 7

Regression Coefficients for Retention Program Students $(N=126)$

\begin{tabular}{lcccccc}
\hline & $B$ & Wald & $d f$ & Sig & $\operatorname{Exp}(\mathrm{B})$ & 95\% Confid Interval \\
\hline Workshops & 4.280 & 9.607 & 1 & .002 & 72.249 & $4.824,1082.050$ \\
Gender & -.579 & .087 & 1 & .768 & .561 & $.012,26.213$ \\
Ethnicity & .964 & .513 & 1 & .474 & 2.623 & $.188,36.671$ \\
GPA & 3.351 & 4.609 & 1 & .032 & 28.519 & $1.339,607.514$ \\
Constant & -20.635 & 8.070 & 1 & .005 & .000 & \\
\hline
\end{tabular}

Cox \& Snell R Square $=.665$

In order to promote social engagement on campus, program participants were also invited to social events such as the Excellence Awards Ceremony that recognizes participants for their academic performance; MLK Movie Night; field trips to Disney World; Career Trip to University of Central Florida, and a visit to the Vizcaya Museum in Miami, Florida. At least half of the participants took advantage of these events, especially the trip to Disney World. On this trip, students stayed at an Orlando hotel for one night where at least four students shared one room, allowing them to get to know each other better. They also rode the bus for over 6 hours, which also created more opportunities to form closer bonds. These social events added a cultural enrichment to their university experience and were voluntary.

Ho5: Attending social events is not related to graduation.

As shown in Table 8, attending social events was significantly related to graduation while holding the control variables of gender, ethnicity, and college GPA constant. Even though not purely academic, in some way these social events appeared to 
create a connection between the students and the university. This social connection was positively associated with persistence, consistent with Tinto's (1987) theory of social engagement and with prior research focused on traditional college students. Students attending social events had a much higher odds of graduating than those who did not attend. Since the Cox and Snell R2 is .56, then approximately $56 \%$ of the variance is explained by the model.

Table 8

Regression Coefficients for Retention Program Students $(N=126)$

\begin{tabular}{lcccccc}
\hline & $B$ & Wald & $d f$ & Sig & $\operatorname{Exp}(\mathrm{B})$ & $95 \%$ Confid Interval \\
& & & & & & \\
\hline Social Events & 3.837 & 22.694 & 1 & $>.001$ & 46.387 & $9.567,224.907$ \\
Gender & -.250 & .063 & 1 & .802 & .779 & $.110,5.520$ \\
Ethnicity & 1.953 & 5.971 & 1 & .015 & 7.050 & $1.472,33.775$ \\
GPA & 1.447 & 3.664 & 1 & .056 & 4.248 & $.966,18.684$ \\
Constant & -7.863 & 8.029 & 1 & .005 & .000 & \\
\hline
\end{tabular}

Cox \& Snell R Square $=.560$

Prior research (Tinto, 1987) with traditional college students has shown academic advising has been associated with college persistence. As a part of the retention program it was important to examine whether this component of the program was significantly associated with graduation while considering the control variables.

Ho6: Attending advising sessions is not related to graduation.

Table 9 below shows that attending advising sessions was not significantly related to graduation at the $p<.05$ level. Since the Cox and Snell R2 is .704, then approximately $70 \%$ of the variance is explained by the model. 
Table 9

Regression Coefficients for Retention Program Students $(N=126)$

\begin{tabular}{lcccccc}
\hline & $B$ & Wald & $d f$ & Sig & $\operatorname{Exp}(\mathrm{B})$ & $95 \%$ Confid Interval \\
\hline Advising & 5.716 & 3.454 & 1 & .063 & 303.708 & $.732,126028.38$ \\
Gender & -4.121 & .123 & 1 & .725 & .016 & $.000,1.6 \mathrm{E}+008$ \\
Ethnicity & -4.207 & .690 & 1 & .406 & .015 & $.000,304.547$ \\
GPA & 3.683 & 2.623 & 1 & .105 & 39.755 & $.461,3428.359$ \\
Constant & -26.284 & 2.138 & 1 & .144 & .000 & \\
\hline
\end{tabular}

Cox \& Snell R Square $=.704$

Overall, the results showed that three of the program features were predictors of graduation and the fourth, advising, while not significantly related as a predictor of graduation at the $p<.05$ level, approached significance at $p<.063$.Clearly, retention program students who participated in tutoring and attended workshops and social events were more likely to graduate than students who did not take advantage of these program features. Further as shown in the analysis in research question one, overall, participation in the program was associated with persistence when program participants were compared to non-participants.

\section{Research Question 3}

The third research question asked whether predictors of GPA could be identified for students in the retention program using program and descriptive variables. Because GPA was treated as a continuous variable, these analyses used Ordinary Least Squares (OLS) regression. Multiple linear regression models were used to test the hypotheses using a probability level of $p=.05$ or less for accepting or rejecting the null hypothesis. 
The correlation matrix showed that all participation variables, except for advising, were significantly correlated. All these participation variables overlapped (multicollinearlity), so I did not consider them in the same model at the same time. Therefore, I considered each variable separately with the control variables of gender, ethnicity, and college GPA. The null hypotheses were as follows:

$\mathrm{Ho}_{7}$ : Attending tutoring is not a predictor of college GPA of participants in the retention program.

Free academic tutoring was available to students in key first-year courses, such as college algebra, chemistry, biology, and finite mathematics. This service was utilized by more than half of the students in the retention program. Students who demonstrated an academic need in these areas were required to attend. This analysis tested whether tutoring was significantly associated as a predictor variable for college GPA among those students who were in the retention program.

As Table 10 shows, tutoring was shown to be significantly related as a predictor of GPA at $p<.05$ level for participants in the retention program, while holding the control variables gender and ethnicity constant. The results also showed that gender was positively significant to GPA at $p<001$ and ethnicity was not a predictor of GPA for retention program participants. For those students required to attend or for those students who felt the need for tutoring, tutoring was positively associated with academic success. Considering all students who started the program were classified as academically underprepared, it is important to note tutoring was associated with success. The pseudo $\mathrm{R} 2$ is an estimate of the explained variance, therefore, if the Cox \& Snell R2 is .27 then approximately $27 \%$ of the variance is explained by the model. 
Table 10

Regression Coefficients for Retention Program Students (N=126)

\begin{tabular}{lccc}
\hline & $B$ & $t$ & Sig. \\
\hline Tutoring & .127 & 4.836 & $<.001$ \\
Gender & -.471 & -3.405 & .001 \\
Ethnicity & .084 & .985 & .327 \\
Constant & 2.528 & 8.653 & $<.001$ \\
\hline
\end{tabular}

\section{Cox \& Snell R Square $=.270$}

The retention program also offered voluntary workshops on various topics, including study skills, time management, career development, and leadership development for program participants. At least one third of retention program participants took advantage of these workshops.

$\mathrm{Ho}_{8}$ : Attending workshops is not a predictor of college GPA of participants in the retention program.

As shown in Table 11 below, attending workshops was found to be a significant predictor of college GPA while holding the control variables of gender and ethnicity constant. Therefore, among retention program participants, those who attended workshops were more likely to have higher GPAs than those who did not. Since the Cox and Snell R2 is .265 , then approximately $27 \%$ of the variance is explained by the model. 
Table 11

Regression Coefficients for Retention Program Students (N=126)

\begin{tabular}{lccccc}
\hline & $B$ & $S E$ & Beta & $t$ & Sig. \\
\hline Workshops & .129 & .027 & .381 & 4.728 & $<.001$ \\
Gender & -.462 & .139 & -.267 & -3.316 & .001 \\
Ethnicity & .057 & .086 & .052 & .664 & .508 \\
Constant & 2.603 & .287 & & 9.054 & $<.001$ \\
\hline
\end{tabular}

Cox \& Snell R Square $=.265$

Ho9: Advising is a predictor of college GPA of participants in the retention program. As part of being in the retention program, participants could receive advising at least twice per month. Some students took advantage of this service more than others. At least one third of retention program participants took advantage of advising sessions Advising was significantly related to college GPA at the $p<.05$ level, while holding the control variables ethnicity and gender constant (see Table 12). Gender was also a significant predictor of college GPA with women more likely to have a higher GPA than men. Since the Cox and Snell R2 is .323, then approximately $32 \%$ of the variance is explained by the model. 
Table 12

Regression Coefficients for Retention Program Students (N=126)

\begin{tabular}{lccccc}
\hline & $B$ & $S E$ & Beta & $t$ & Sig. \\
\hline Advising & .099 & .017 & .456 & 5.900 & $>.001$ \\
Gender & -.434 & .134 & -.250 & -3.249 & .002 \\
Ethnicity & .061 & .082 & .056 & .747 & .456 \\
Constant & 2.487 & .276 & & 9.019 & $>.001$ \\
\hline
\end{tabular}

Cox \& Snell R Square $=.325$

$\mathrm{Ho}_{10}$ : Attending social events is not a predictor of college GPA of participants in the retention program.

Table 13 shows that attending social events was a significant predictor of college GPA of participants in the retention program. As shown in Table 13, attending social events was significantly related to college GPA at $p<.05$ level, while holding the control variables of gender and ethnicity constant. Even though not purely academic, in some way these social events created a connection between the student and the university. This social connection was positively associated with college GPA, consistent with prior research focused on traditional college students. Students attending social events had a higher college GPA than those who did not attend. Since the Cox and Snell R2 is .399, then approximately $40 \%$ of the variance is explained by the model. 
Table 13

Regression Coefficients for Retention Program Students (N=126)

\begin{tabular}{lccccc}
\hline & $B$ & $S E$ & Beta & $t$ & Sig. \\
\hline Social Events & .429 & .058 & .539 & 7.334 & $>.001$ \\
Gender & -.381 & .127 & -.220 & -3.007 & .003 \\
Ethnicity & .152 & .078 & .140 & 1.953 & .053 \\
Constant & 2.220 & .269 & & 8.243 & $>.001$ \\
\hline
\end{tabular}

\section{Cox \& Snell R Square $=.399$}

To summarize, all of the program features, workshops, advising, social events, and tutoring were significantly related to college GPA, indicating that retention program students who took advantage of program services, had higher GPAs. Another important finding was that gender was also a significant predictor of college GPA with female students having a higher GPA than male students.

\section{Conclusion}

Retention programs to promote college student persistence are many, but rigorous research to examine these programs is much scarcer. The research that includes large racial/ethnic minority samples and actually examines the program features is even more limited. These analyses confirmed a strong relationship between program participation and student retention and between several program features and student retention and college GPA.

The study included 292 low-income, under-prepared, first generation university students. Data were collected from university archival records and included college GPA, SAT scores, gender, ethnicity, and group (retention or non-retention program 
participation). Additional data collected for the 126 retention program students included program participation, such as the number of advising, tutoring, social events, and workshops attended by the retention program students. Significant differences were found in graduation for students in the retention and non-retention program as well as for SAT scores and GPA. Students in the retention program had lower SAT scores on average but earned a higher GPA than non-retention students. For the students in the retention program, all program features were found to be significant predictors of graduation at $p<.05$, except advising, which approaches significance at $p<.063$. College GPA was found to be a predictor of graduation for all students. Participation in tutoring, workshops, and social events were also predictors of graduation. Gender was also a predictor of graduation with females more likely to graduate than males. Participation in these program features also were significant predictors of retention students' GPA. Chapter 5 reviews the findings of the study and relates the findings to current literature as well as discussing the implications of the study, suggestions for future research, and study limitations. 


\section{CHAPTER V \\ DISCUSSION}

The preceding chapters introduced the research questions and the context for the study, including the theoretical framework, a review of the relevant literature, and a description of the research method and analyses of data. This chapter concludes the dissertation by offering a discussion of findings from the study, theoretical implications, limitations of the study, and suggestions for future research.

This study tested hypotheses developed from the literature regarding academic and social integration theory (Tinto, 1987). The hypotheses addressed the differences in persistence rates and other academic characteristics of under-prepared, low-income, first generation college students who participated and did not participate in a retention program. The hypotheses also addressed whether scores, GPA, social events, tutoring, workshops, advising, gender, and ethnicity predict persistence of participants in the retention program.

In addressing the first research question regarding whether there are differences in persistence and graduation rates and other academic characteristics of under-prepared, low-income, first generation college students who participate and do not participate in the retention program, the results indicated that there were significant differences in graduation rates and other academic variables, such as GPA of students who participated in the retention programs as opposed to students in the control group. Students in the retention program had a $65.1 \% 6$-year graduation rate compared to $46.6 \% 6$-year graduation for students in the control group. This percentage difference was shown to be significant. 
This retention program followed Tinto's (1975) theory by combining academic and social integration strategies that were focused on helping participating students in the first year. During the first year, students were usually at the highest risk of attrition especially when compounded with other challenges, such as first generation and lowincome status and being academically under-prepared. The study also predicted that GPA, social activities, tutoring, workshops, advising, gender, and ethnicity are predictors of persistence and graduation. Based on Tinto's academic and social integration theory, the academic support services, such as tutoring and advising, as well as the social support, including social events and being a part of what can be described as a learning community, were associated with the graduation rates of students in the retention program.

It should be noted that whereas Tinto's (1987) theory described the assimilation of students into the culture of the university as similar to the rite of passage from youth to adulthood within a culture, for minority students this assimilation would constitute "cultural" suicide in moving from a familiar culture to a foreign one. According to Tierney (1992), who discussed Native American students, minority students would have a difficult transition into this new culture. I suggest that this retention program, however, provides the "interpreter" and a safe place that prevents participants from committing cultural suicide, and hence contributed to their persistence. The retention program can assist minority students in making sense of the majority dominated university culture and the rules and expectations. The physical location or offices of the program can also be experienced as a safe haven from the more challenging broader university. This assists in developing a bi-cultural experience of appreciation for both cultures rather than a cultural 
suicide to leave the home culture for the university culture. This type of research suggests new ideas or can push the theory of academic and social integration to become more multicultural.

One of the hypotheses tested was that there would be no differences in academic ability (GPA and SAT scores) for students participating in the retention program and students not participating in the retention program. The results indicated that there were statistically significant differences for SAT and for GPA .Inspection of the means for the retention and non-retention groups indicated the non-retention group had a higher SAT score on average $(M=909.94)$ than did students in the retention program $(M=869.78)$. However, on average retention program participants had a higher GPA $(M=2.72)$ than did students not in the retention program $(M=2.47)$. This suggests that those who did not take advantage of the program were slightly better prepared academically than those who did participate, yet those who participated did better academically with higher college grades.

The study also tested the hypotheses that tutoring, advising, social events, workshops, gender, and ethnicity are predictors of graduation or persistence. The results showed that tutoring, attending social events, and workshops were significantly positively related to graduation. Whereas advising was shown not to be significantly related to graduation, it approached significance at $p<.063$. Hispanic students in the retention program were more likely to graduate than non-Hispanic students with Non-Hispanic students 1.2 times less likely to graduate than Hispanic students. The results also indicated that males were 2.9 times less likely to graduate than females. Being in the experimental group was also a predictor of graduation with students in the retention 
program 2times more likely to graduate than students who were not in the retention program.

\section{Theoretical Implications}

Tinto (1987) reasoned that the student's level of integration into the culture of the institution's academic and social structures is related to the decision to drop out or persist in university studies. The results of the present study supports this theory in that participants in the retention program were more academically and socially integrated within the retention program and persisted at a higher rate (65.1\%) than students who were not in the retention program $(46.6 \%)$ who might not have had the opportunity to make the academic and social connections within the larger university setting. The results of the study also showed that students' level of participation in the retention program also was positively associated with graduation and persistence of the participants.

Tinto's (1993) assertion that students need to break away from past associations and traditions to become better integrated into the college's social and academic milieu did not apply in this study. This may be due to the ethnic composition of the university where this study was conducted. More than $50 \%$ of the student population was Hispanic, and this ethnic composition was also represented in the overall sample studied. The study also showed that Hispanic students were 2 times more likely to graduate than nonHispanics. Tierney (1992) argued that this rites of passages model from which Tinto drew this concept of breaking away is not applicable to minority college students because the model was intended to describe developmental progression within a culture rather than assimilation from one culture to another. Furthermore, given that minority students' 
cultural backgrounds often differ from the Eurocentric frameworks upon which the norms and values at predominantly PWIs are based, Tierney argued that this aspect of Tinto's theory ignores bicultural integration, or the ability of minority students to succeed at college while being part of both the majority and minority cultures (Rendon, Jalamo, \& Nora, 2000). In contrast, for students at this institution, it was somewhat a transition within culture as the students moved from primarily Miami high schools, which have high Hispanic populations, to an HSI. In this study it appears that students in the retention program adapted to Tinto's stage of incorporation, which is marked by students finding and adopting norms appropriate to the new college setting and establishing competent membership in the social and intellectual communities of college life (Tinto, 1988).

Like Tinto's (1975) theory, the retention program had a holistic combination of academic and social integration strategies focused on helping participating students in the first year. The first year focus of the intervention was chosen because freshmen are usually at the highest risk of attrition, especially if compounded with other challenges, such as first-generation status, low-income status, and being academically underprepared. Like Tinto's theory of social integration, strong social networks among program participants and with staff were promoted on the basis of similar backgrounds. Academic intervention strategies included peer tutoring, academic advising, workshops, and an early alert warning system and were implemented to foster academic integration consistent with Tinto's theory. All of these intervention strategies were found to have a positively significant association with persistence and graduation rates for students in the retention program. 
In addition, literature on learning communities further supports the theoretical framework on student retention by Tinto (1987), who posited that "interactions among different individuals within the academic and social systems of the institutions lead individuals of different characteristics to withdraw from that institution prior to degree completion" (p. 113). The learning community's model of academic and social integration increases students' connection with the college in general and with the learning process specifically (Tinto, Russo, and Kadel (1994). In this study, all 126 participants are considered part of the learning community by their involvement in the retention program. The fact that they are from similar academic, economic, and social backgrounds also support the strong bonds that they were able to form within the broad context and diversity of the larger university. Tinto, Russo, and Kadel (1994) also found that students in a learning community had better grades and were more likely to remain in college. This is consistent with the present study of at-risk students because students in the retention program had higher GPAs and higher persistence rates than students who were not in the retention program.

\section{Limitations of the Study}

A common weakness of ex post facto research is that the design is not capable of controlling the confounding effects of self-selection and lack of random sampling (Newman\& Newman, 1994). It is correlational and cannot appropriately confirm causal relationships. However, this study only claims to predict persistence patterns based on the independent variables in the model. Further, there may be differences among students who were born in the U.S. and recent immigrant students, and there were no data on immigration status. Also, students self-selected into the treatment group. There may be a 
self-esteem factor or other motivational factors for which students chose to participate in the intervention. Students may wish to avoid being associated with a program known to be for at-risk students and not choose to participate. Conversely, highly motivated students may take advantage of all available services in order to succeed. To the extent possible, the selection criteria and covariates control for factors known to be associated with persistence. This study removed the variability in a number of student characteristics known to be associated with retention, such as academic preparation, family income, and first-generational status, by including only those students. Further this study controlled for GPA, ethnicity, and gender in the analyses of the program features. Considering these key variables were accounted for, the concerns resulting from lack of random sampling in ex post facto research were addressed as well as possible.

This study was limited to a particular retention program at an urban, public university where the cultural diversity is somewhat unique. The 292 students who fit the criteria for this study were 56\% African American and 40\% Hispanic while the remaining $4 \%$ were a combination of other ethnic/racial groups. The study sample was representative of the first-generation, underprepared students who attend the institution. This study is not generalizable to traditional White students at a PWI, but the results have applicability beyond this one campus to many other minority serving programs.

\section{Suggestions for Future Research}

Although this study was contextualized to this particular campus, the sample size, comparison group of non-participants, and variability within the sample suggest broader implications for the results. It would be worthwhile to test if the intervention strategies that were utilized with the participants in the study could be expanded to other groups of 
students, for example students who are not only first generation but students for whom English is their second language, especially at an HSI. Also, there could be more forceful collection of data to include student employment data, and more nuanced ethnicity and race data. In a contemporary context, it is difficult to know what race and ethnic terms mean. For example, many Black Caribbean students would not identify with the term African American but would with the term Black and Hispanic students are uncomfortable being excluded from the White or Black categories. Research studies examining the relationship of institutional retention efforts on persistence and graduation have been minimal, and institutional program evaluations have lacked the necessary rigor to meet accepted standards for published research (Braxton, McKinney, \& Reynolds, 2006); Patton, Morelon, Whitehead \& Hossler, 2006). Therefore, quasi-experimental comparison studies such as this one are necessary to help examine the usefulness of institutional retention programming. The results of this study showed that students in the retention performed better academically and had higher graduation and persistence rates than students who were not part of the program, so institutions could provide more of the services that are provided by this retention program that could improve the retention and graduation rates of their student body.

There is also evidence that while academic integration strategies predicts persistence, the social integration strategies are also predictors of persistence. Many institutions provide some type of academic outreach to first-year students, but for first generation, low-income students, this may not be enough to retain them.

This retention program services also predicts the graduation rates and college GPA of participants who are first-generation, low-income, under-prepared students, so 
higher education administrators can choose to increase support services similar to those utilized by the program staff in order to improve persistence rates and college GPA at their respective institutions. Thus his study has provided valuable information on students from a majority minority institution and the strategies that are predictors of persistence and graduation. 


\section{REFERENCES}

Adelman, C. (1999). Answers in the tool box: Academic intensity, attendance patterns, and bachelor's degree attainment. Washington, DC: National Center for Education Statistics.

Ancis, J., Sedlacek, W.E., \& Mohr, J.J. (2000).Student perceptions of campus cultural climate by race. Journal of Counseling and Development, 78(2), 180-185.

Astin, A. (1975). Preventing students from dropping out. San Francisco, CA: JosseyBass.

Astin, A. (1982). Minorities in American higher education: Recent trends, current prospects, and recommendations. San Francisco: Jossey-Bass, Inc., Publications.

Astin, A. (1993). What matters in college: Four critical years revisited. San Francisco, CA: Jossey-Bass.

Bean, J. P. (1985). Interaction effects based on class level in an explanatory model of college student dropout syndrome. American Educational Research Journal, $22(1), 35-64$.

Bean, J.P., \& Metzner, B.S. (1985).A conceptual model of nontraditional undergraduate student attrition. Review of Educational Research, 55(4), 485-540.

Braxton, J.M., \& Lien, L.A. (2000). The viability of academic integration as a central construct in Tinto's interactionalist theory of college student departure. In J.M. Braxton (Ed.), Reworking the student departure puzzle, (pp.11-28) Nashville, TN: Vanderbilt University Press.

Braxton, J.M., McKinney, J.S. \& Reynolds, P.J. (2006). Cataloging institutional efforts to understand and reduce college student departure. New Directions for Institutional Research, 130, 25-32.

Bui, K.V. (2002). First-generation college students at a four-year university: Background characteristics, reasons for pursuing higher education, and first-year experiences. College Student Journal, 36(1), 3-11.

Cabrera, A.F., Nora, A., \& Castaneda, M.B. (1992). The role of finances in the persistence process: A structural model. Research in Higher Education, 33(5), 571-593.

Carter, J.A., Chase, P.B., \& Folger, W.A. (2004).Supporting first generation college freshmen with small group intervention. College Student Journal, 38(3), 472-476. 
Chaney, B., Muraskin, D.L., Cahalan, W.M., \& Goodwin, D. (1998).Helping the progress of disadvantaged students in higher education: The federal student support services program. Educational Evaluation and Policy Analysis, 20(3), 197-215.

Choy, S. (2001).Students whose parents did not go to college. Washington, DC: National Center for Education Statistics.

Durkheim, E. (1951). Suicide: A study in sociology. In G. Simpson (Ed.), Translated by Spaulding, J.A. \& Simpson, E. Originally published in 1897. Glencoe, IL: Free Press.

Fidler, P., \& Godwin, A.M. (1994). Retaining African American students through the freshman seminar. Journal of Developmental Education, 17(3), 34-36, 38, 40.

Fullilove, R.E., \& Treisman, P. (1990). Mathematics achievement among African American undergraduates at the University of California, Berkley: An evaluation of the mathematics workshop program. Journal of Negro Education, 59(3), 463478.

Gardner, J. N. (1996). Helping America's first generation college students: A bottom line list of what institutions of higher learning must do. About Campus, 31-32.

Hahs-Vaughn, D. (2004). The relationship of parents' education level on college students: An analysis using the beginning postsecondary student's longitudinal study 1990-92/94. Journal of College Student Development, 45(5), 483-500.

Hall, B. (1999).College warm-up: Easing the transition to college. Journal of College Student Personnel, 23,280-281.

Harrell, E.P.,\& Forney, S.W. (2003). Ready or not, here we come: Retaining Hispanic and first-generation students in postsecondary education. Community College Journal of Research and Practice, 27, 147-156.

Himelhock, C.R., Nichols, A., Ball, S.R.,\& Black, L.C. (1997, ). A comparative study of the factors which predict persistence for African American students at historically black institutions and predominantly white institutions. Paper presented at The Association for the Study of Higher Education (ASHE) Annual Meeting.

Inman, W.E.,\& Mayes, L. (1999). The importance of being first: Unique characteristics of first generation community college students. Community College Review, $26(4), 3-22$.

Ishitani, T.T. (2003). A longitudinal approach to assessing attrition behavior among firstgeneration students: Time-varying effects of pre-college characteristics. Research in Higher Education, 44(4), 433-449. 
Just, H. D. (1999). Minority retention in predominantly white universities and colleges: The importance of creating a good "fit". Paper, ED.

Kadel, S., Russo, P.,\& Tinto, V. (1995).Learning communities and student involvement in the community college. In J. Gardner \& J. Hankin (Eds.), Promoting new student success in community colleges. Columbia: National Resource Center for the Freshman Year Experience, The University of South Carolina.

Levin, E.M., \&Levin, R.J. (1991). A critical examination of academic retention programs for at-risk minority college students. Journal of College Student Development, $32,323-334$.

Littleton, R.A. (2001, November). African American student persistence at small colleges in Appalachia: A qualitative study. Paper presented at Association for the Study of Higher Education Annual Conference, Richmond, VA.

Liu, R., \& Liu, E. (2000). Institutional integration: An analysis of Tinto's theory. Paper presented at the AIR Forum.

MacDonald, G. (2005). Defining college readiness from the inside out: First generation student perspectives. Community College Review, 33(1) 22-37.

McKenzie, D.F. (2005). Reducing attrition rates for Maori students. Journal of Developmental Education, 28(3), 12-18.

Mertler, C.A. \& Vannatta, R.A. (2001). Advanced and Multivariate Statistical Methods: Practical Application and Interpretation. Los Angeles, CA: Pyrczak Publishing.

Metzner, B.S., \&Bean, J.P.(1987). The estimation of a conceptual model of nontraditional undergraduate student attrition. Research in Higher Education, 27(1), $15-38$.

Moore, W., Jr., \& Carpenter, L.N. (1985). Academically underprepared students. In L. Noel, R. Levitz, D. Saluri, \& Associates (Eds.), Increasing Student Retention (pp. 95-115). San Francisco, CA: Jossey-Bass.

Nauman, C.W., Bandalos, D., \& Gutkin, B.T. (2003).Identifying variables that predict college success for first-generation college students. Journal of College Admissions, 181, 4-9.

Newman, P.R., \& Newman, B.M. (1999). What does it take to have a positive relationship on minority students' college retention? Adolescence, 34(135), 483492.

Newman, I., \& Newman, C. (1994). Conceptual Statistics for Beginners. Lanham, MD: University Press of America. 
Nora, A., \&Cabrera, F.A. (1993). The construct validity of institutional commitment: A confirmatory factor analysis. Research in Higher Education, 34(2), 243-251.

Nora, A., \&Cabrera, F.A. (1996). The role perceptions in prejudice and discrimination and the adjustment of minority students to college. Journal of Higher Education, 67(2), 119-148.

Pascarella, E., \& Terenzini, P. (1991). How college affects students. San Francisco, CA: Jossey-Bass.

Pascarella, E., \& Terenzini, P. (1998). Studying college students in the $21^{\text {st }}$ century: Meeting new challenges. Review of Higher Education, 21(2), 151-165.

Pascarella, E.T., Pierson, C.T., Wolniak, G.C.,\& Terenzini, P.T. (2004). First-generation college students: Additional evidence on college experiences and outcomes. The Journal of Higher Education, 75(3), 249-284.

Pike, G.R.,\& Kuh, G.D. (2005). First-and second generation college students: A comparison of their engagement and intellectual development. The Journal of Higher Education, 76(3), 276-300.

Pratt, P., \& Skaggs, C. (1989). First-generation college students: Are they at greater risk for attention than their peers? Research in Rural Education, 6(2), 31-34.

Putton, L.D., Morelon, C., Whitehead, D.M., \& Hossler, D. (2006). Campus-based retention initiatives: Does the emperor have clothes? New Directions for Institutional Research, 13, 9-24.

Rendon, L. I., Jalamo, R.E., \&Nora, A. (2000).Theoretical considerations in the study of minority student retention in higher education. In J.M. Braxton (Ed.), Reworking the student departure puzzle (pp. 127-156). Nashville, TN: Vanderbilt University Press.

Reyes, N. (1997). “Holding on to What They've Got: Analysis of Programs Implemented by Six Institutions to Keep College Students in School." Black Issues in Higher Education, 13(26), 36-40.

Richardson, R.C., Jr., \& Skinner, C.F. (1992).Helping first generation minority students achieve degrees. In L.S. Zwerling \& H.B. London (Eds.), First generation students: Confronting the issues (pp. 29-43). New Directions in Community Colleges(80), San Francisco, CA: Jossey-Bass.

Somers, P., Woodhouse, S., \& Cofer, J. (2004).Pushing the boulder uphill: The persistence of first-generation college students. NASPA Journal, 41, 418-435. 
Spady, W. (1970). Dropouts from higher education: An interdisciplinary review and synthesis. Interchange, 1, 64-85.

Stage, F.K., \& Hossler, D. (2000).Where is the student? Linking student behaviors, college choice, and college persistence. IN J.M. Braxton (Ed.), Reworking the student departure puzzle (pp. 170-194). Nashville, TN: Vanderbilt University Press.

Strage, A. (1999). Social and academic integration and college success: Similarities and differences as a function of ethnicity and family education background. College Student Journal, 33, 198-205.

Taylor, K., Moore, W.S., MacGregor, J. (2003). Learning communities research and assessment: What we know now (National Learning Communities Project Monograph Series.). Olympia, WA: The Evergreen State College, Washington Center for Improving the Quality of Undergraduate Education, and the American Association for Higher Education.

Terenzini, P.T., Rendon, L., Upcraft, L., Millar, S., Allison, K., Gregg, P., Jalamo, R. (1994). The transition to college: Diverse students, diverse stories. Research in Higher Education, 35(1), 57-73.

Terenzini, P., Springer, L., Yaeger, P.M., Pascarella, E.T., \& Nora, A. (1996). Firstgeneration college students: Characteristics, experiences and cognitive development. Research in Higher Education, 37(1), 1-22.

Tierney, W.G. (1992). An anthropological analysis of student participation in college. Journal of Higher Education, 63, 603-617.

Tierney, W.G.(1999). Models of minority college-going and retention: Cultural integrity versus cultural suicide. Journal of Negro Education, 68(1), 80-91.

Tierney, W.G. (2000). On translation: From research findings to public utility. Theory into Practice, 39(3), 185-190.

Ting, S.R. (1998). Predicting first-year grades and academic progress of college students of first-generation and low-income families. Journal of College Admission, 158, $14-23$.

Tinto, V. (1975). Dropout from higher education: A theoretical synthesis of recent research. Review of Educational Research, 45, 89-125.

Tinto, V. (1987).Leaving college: Rethinking the causes and cures of student attrition. Chicago, IL: The University of Chicago Press. 
Tinto, V. (1993). Stages of student departure: Reflections on the longitudinal character of student leaving. Journal of Higher Education, 59,438-455.

Tinto, V. (1998). Colleges as communities: Taking research on student persistence seriously. Review of Higher Education, 21(2), 166-177.

Tinto, V., Russo, P., \& Kadel, S. (1994). Constructing educational communities: Increasing retention in challenging circumstances. Community College Journal, 64, 26-30.

Tracey, T.J.,\& Sedlacek, W.E. (1984).Noncognitive variables in predicting academic success by race. Measurement and Evaluation in Guidance, 16(4), 171-178.

Tracey, T.J., \& Sedlacek, W.E. (1985).The relationship of noncognitive variables to academic success: A longitudinal comparison by race. Journal of College Student Personnel, 26(5), 405-410.

Ugbah, S.D.,\& Williams, S.A. (1989).The mentor-protégé relationship: Its relationship on Blacks in predominantly White institutions. In J.C. Elam (Ed.), Blacks in higher education: Overcoming the odds. Lanham, MD: University Press of America.

University Website (2008).

U.S. Department of Education, National Center for Educational Statistics. (1995-1996) Beginning postsecondary student's longitudinal study, first follow-up (BPS: 96/98). Washington, DC: Author.

Van Gennep, A. (1960). The rites of passage. (M. Vizedon \& G. Caffee, Trans.). Chicago, IL: The University of Chicago Press.

Warburton, E., Bugarin, R., \& Nunez, A. (2001).Bridging the gap: Academic preparation and postsecondary success of first-generation students (NCES 20012001-153). Washington, DC: National Center for Education Statistics, U.S. Government Printing Office.

Yorke, M. (1999). Benchmarking academic standards in the UK. Tertiary Education and Education and Management, 5(1), 81-96. 
VITA

DORRET E. SAWYERS

OBJECTIVE: $\quad$ To effectively plan, administer and supervise collegiate programs and services at the university level.

EDUCATION: Doctoral Candidate, Florida International University, College of Education, Major - Higher Education Administration.

Anticipated graduation -Fall 2011.

UNIVERSITY OF MISSOURI-COLUMBIA, Columbia, MO

MPA, Public Administration, May, 1987

TUSKEGEE UNIVERSITY, Tuskegee, AL

B.S. (High Honors), Business Administration, May, 1984

HONORS: $\quad$ Ponder Graduate Fellowship, 1984, Dean's List, 1981-84; Honor Roll, 1981-84; Most Developed Student Award; Recognition, Student Organization Council, Black Student Union, FIU OpaLocka Scholarship Committee; Who's Who Among Students at US Colleges \& Universities, 1983, Nominee-Team Player Award, Finalist - Access \& Equity Award, Division of Student Affairs, FIU, Quiet Storm Award, Women Power Caucus Conference, Ft. Lauderdale, Florida, April 16, 2004, Student Affairs Service Award, 2010.

JOB RESPONSI-: $\quad$ FLORIDA INTERNATIONAL UNIVERSITY, Miami, FL BILITIES:

2004-2011 Director, Multicultural Programs and Services, BBC, FIU

- Plan, monitor and evaluate all program components

- Coordinate office retention programs

- Authorize expenditures from office budget

- Responsible for continuous progress toward office objectives

- Supervise staff comprising, one associate director, a secretary, two graduate assistants and four tutors.

- Prepare necessary reports to meet University requirements.

- Develop collaborative strategies with other university units and outside agencies

- Dissemination of information regarding all programs; write and submit grant proposals. 
$2 / 97-8 / 04$

$2 / 92-2 / 97$

$8 / 87-7 / 91$
Acting Director, SSSP, Multicultural Programs, FIU, UP

- Responsible for planning, implementing and evaluating programs and services related to the academic, social and cultural development of currently enrolled minority students in accordance with FIU and State University System retention goals, policies, procedures and guidelines.

- Develop and promote more effective counseling and advising programs to include developmental workshops and academic counseling

- Supervise collegiate staff and ensure that program goals and objectives are satisfactorily met

- Coordinate retention program for targeted students, primarily students on warning and probation.

- Collect and analyze data to prepare monthly, semester and annual reports that impact targeted student population

- Supervise one assistant director, one coordinator and a senior secretary

- Supervise tutorial program that serves all enrolled students at the university

- Establish evaluation procedures for the tutorial and advising components

- Assist in the preparation of grant proposals

Associate Director, Minority Student Services (currently MPAS)

- Coordinate and supervise the Tutorial Program

- Responsible for preparing monthly, semester and annual reports on program outcomes

- Conduct and plan enhancement workshops that address the growing needs of the collegiate student

- Coordinate and plan activities that enhances the social and cultural development of currently enrolled students

UNIVERSITY OF MISSOURI, Columbia, MO

Fiscal Analyst, Investments and Trusts

- Forecasted, planned and managed cash flow

- Created and maintained clearings for investment

- Determined the amount available for investment

- Designed and maintained weekly trial balance on purchases and maturities of various securities 